\title{
Variedades de Durazno y Nectarina en la Florida ${ }^{1}$
}

\author{
Ali Sarkhosh, Mercy Olmstead, José Chaparro, Pete Andersen, Jeff Williamson, and Tatiana \\ Sanchez ${ }^{2}$
}

El programa de cultivo de fruta de hueso empezó en 1952, bajo la dirección del Dr. Ralph Sharpe. La meta principal del programa de cultivo del Dr. Sharpe, era tomar ventaja del clima de la Florida para ofrecer fruta temprano y de alta calidad al mercado (Sherman et. al. 1996). En 1966, Dr. Wayne Sherman se convirtió en el leader del programa de cultivo de fruta de hueso, y continuó enfocándose en el desarrollo de cultivares de durazno con bajo requerimiento de horas frío con pulpa no fundente que se desempeñaran bien en el clima subtropical de la Florida. El cultivador actual de fruta de hueso, Dr. José Chaparro, ha supervisado e iniciado investigación para traer material vegetal único enfocándose en fruta más grande de alta calidad con resistencia a enfermedades y bajos requerimientos de horas frío.

La Universidad de la Florida ha desarrollado cultivares de nectarina y durazno de alta calidad, bajo requerimiento de horas frío, y de maduración temprana que pueden cultivarse desde el Panhandle de la Florida (noroeste del estado) tan al sur como Immokalee. Cultivares de bajas horas frío pueden crecer y producir fruta bajo las condiciones de la Florida que son mucho más cálidas en el invierno que en estados más al norte. Además, la maduración de estos cultivares durante abril y mayo aseguran una ventana de mercado temprano en la primavera para fruta fresca en la Florida antes que duraznos y nectarinas de otros estados sureños y California entren al mercado. Tanto las variedades comerciales como las recomendadas en el jardín abarcan la temporada de crecimiento (Tabla 1).

Los duraznos y las nectarinas son la misma especie, Prunus persica, pero las nectarinas difieren de los duraznos en que carecen de la 'pelusa del durazno'. Por lo tanto, la siguiente discusión se aplica tanto a los duraznos como a las nectarinas, pero en la mayoría de los casos se hará referencia solo a los duraznos. Las ciruelas, la única otra fruta de hueso para la cual tenemos cultivares adecuados en la Florida, están cubiertas en Growing Plums in Florida, otra hoja informativa disponible en http://edis.ifas.ufl.edu/hs250.

\section{Periodos de desarrollo de la fruta y acumulación de frío}

La capacidad de maduración temprana es un rasgo importante para los cultivares de fruta de hueso en Florida. El período desde que la fruta cuaja hasta la madurez, cuando la fruta puede ser cosechada, se llama período de desarrollo de la fruta, o FDP por sus siglas en ingles. El FDP de los cultivares actuales de durazno de Florida es bastante corto: algunos de ellos estarán maduros y listos para la cosecha tan pronto como 60 días después de la fruta se establece. El FDP puede variar con la temperatura durante la temporada de crecimiento, ya que temperaturas más

1. Este documento es Circular 1159, una publicación del Departamento de Ciencias Hortícolas, UF/IFAS Servicio de Extensión. Publicado originalmente en 1995 bajo el título Peaches and Nectarines for Central and North Florida, http://ufdc.ufl.edu/IR00002904/00001. Revisado en mayo 2013 y junio 2016. Repasado y revisado en octubre 2018. Visite el sitio web EDIS en http://edis.ifas.ufl.edu.

2. Ali Sarkhosh, profesor asistente y especialista en Extensión; Mercy Olmstead, exprofesor asistente; José Chaparro, cultivador de fruta de hueso; Pete Andersen, profesor, Departamento de Ciencias Hortícolas, NFREC, Quincy, FL; Jeff Williamson, profesor, Departamento de Ciencias Hortícolas; Servicio de Extensión de UF/IFAS, Gainesville, FL 32611. James Ferguson, profesor jubilado del Departamento de Ciencias Hortícolas, contribuyó en versiones anteriores de esta publicación. La traducción del inglés al español estuvo a cargo de la Doctora en Medicina de Plantas, Tatiana Sanchez, Servicio de Extensión de UF/IFAS en el condado de Alachua.

The Institute of Food and Agricultural Sciences (IFAS) is an Equal Opportunity Institution authorized to provide research, educational information and other services

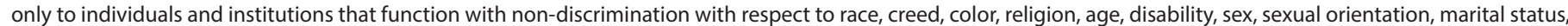

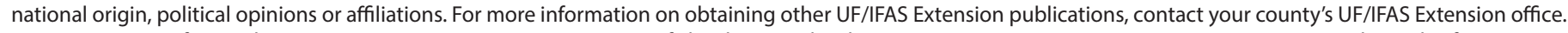
U.S. Department of Agriculture, UF/IFAS Extension Service, University of Florida, IFAS, Florida A \& M University Cooperative Extension Program, and Boards of County Commissioners Cooperating. Nick T. Place, dean for UF/IFAS Extension. 
cálidas comprimen y las temperaturas más frías alargan el FDP. Por lo tanto, el FDP varía de una temporada a otra, y los números presentados son promedios de varios años.

Los cultivares de durazno de bajo requerimiento de horas frío son aquellos que requieren menos unidades de frío (100-250 unidades de frío) que aquellos que se originan en climas templados. Los cultivares de frío moderado se han desarrollado para el norte de Florida, el centro-norte de Florida y el centro-sur de Georgia y requieren un mayor número de unidades de frío (300-525 unidades de frío). Las unidades de frío son variables en todo el estado de Florida y disminuyen a medida que uno se desplaza hacia el sur en el estado (Tabla 2). El requisito de la unidad de frío no siempre está relacionado con el FDP, y algunos cultivares requieren grandes cantidades de frío, pero tienen un FDP corto. Por ejemplo, 'UFGlo' requiere 450 unidades de frío, pero tiene un FDP de 80 días, mientras que 'UFBest' requiere menos de 150 unidades de enfriamiento y tiene un FDP de 95 días (Tabla 3).

Hay varios modelos utilizados para calcular las horas de frío (Weinberger 1956; Richardson et al. 1974; Sharpe et al. 1990). Un modelo en particular que define una unidad de frío como 1 hora por debajo de $45^{\circ} \mathrm{F}\left(7^{\circ} \mathrm{C}\right)$, pero por encima de $32^{\circ} \mathrm{F}\left(0^{\circ} \mathrm{C}\right)$ funciona bien para determinar los rangos de acumulación en duraznos de bajo requerimiento de horas frío. La acumulación durante un período definido (generalmente de noviembre a enero en Florida) se denomina acumulación de unidades de frío. Existen muchas fuentes de las cuales se pueden recopilar estos datos, incluida la Red Automatizada del Clima de Florida (http://fawn.ifas. ufl.edu/) (Fraisse y Whidden 2010). El estado de la Florida tiene varias zonas con diferentes acumulaciones de unidades de enfriamiento (Figura 1) para ayudar a seleccionar un cultivar de durazno.

\section{Hábito de crecimiento del árbol de durazno e identificación de cultivares}

Los arboles de durazno varían en su hábito de crecimiento y a menudo, se puede usar una combinación de vigor del árbol, tipo de flor y estructura de la hoja para identificar los cultivares. Los árboles pueden tener un crecimiento semi-esparcido (por ejemplo, 'UFOne') o semi-vertical (por ejemplo, 'Flordaprince') y pueden ser muy vigorosos (por ejemplo, 'UFSun') o moderadamente vigorosos (por ejemplo, 'Sunbest') en el crecimiento del dosel. Las flores en ciertos cultivares de durazno pueden ser vistosas, con pétalos grandes y rosados; las flores en otros cultivares son no-vistosas, con pétalos rojizos más pequeños (Figura 2). Las glándulas de la hoja en la base de la hoja cerca del pecíolo también se pueden usar en el proceso de identificación. Las glándulas foliares pueden estar ausentes (noglandulares), o pueden ser globosas (redondas) o reniformes (en forma de riñón) (Figura 3).

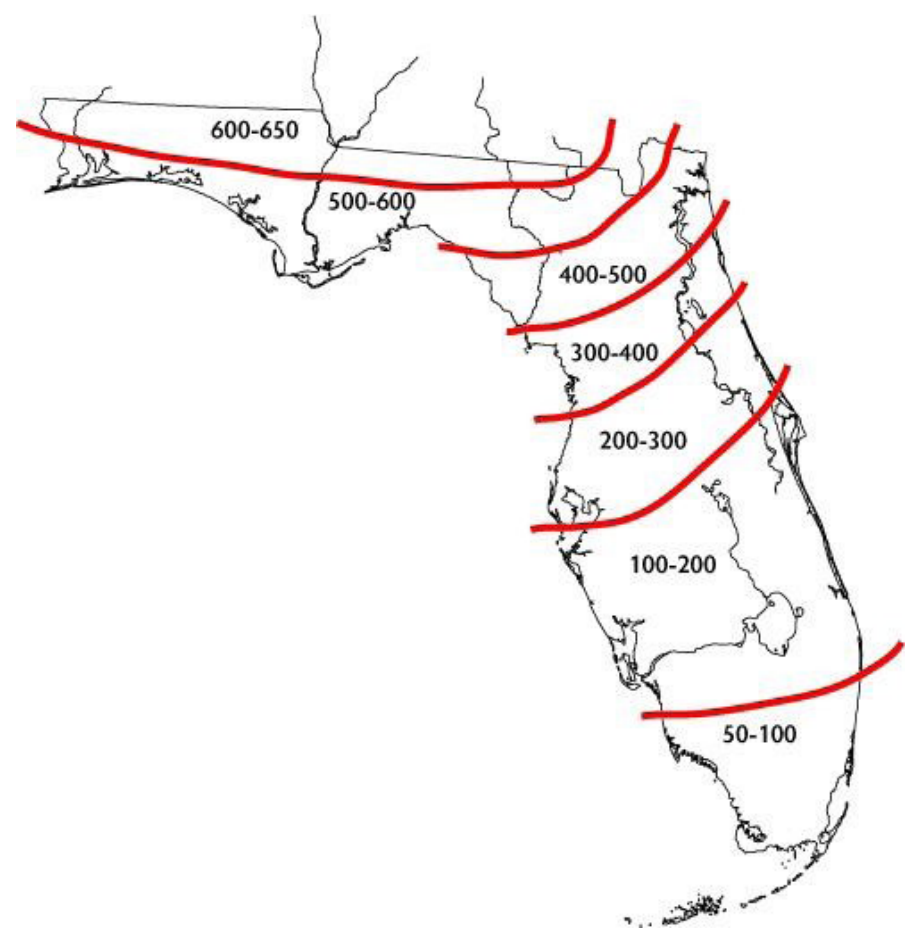

Figura 1. Acumulación de horas frío en Florida (por debajo de $45^{\circ} \mathrm{F}$ $\left[7.2^{\circ} \mathrm{C}\right]$ hasta el 10 de febrero).

Credits: Mapa de contorno cortesía de la Sociedad Histórica del Estado de Florida

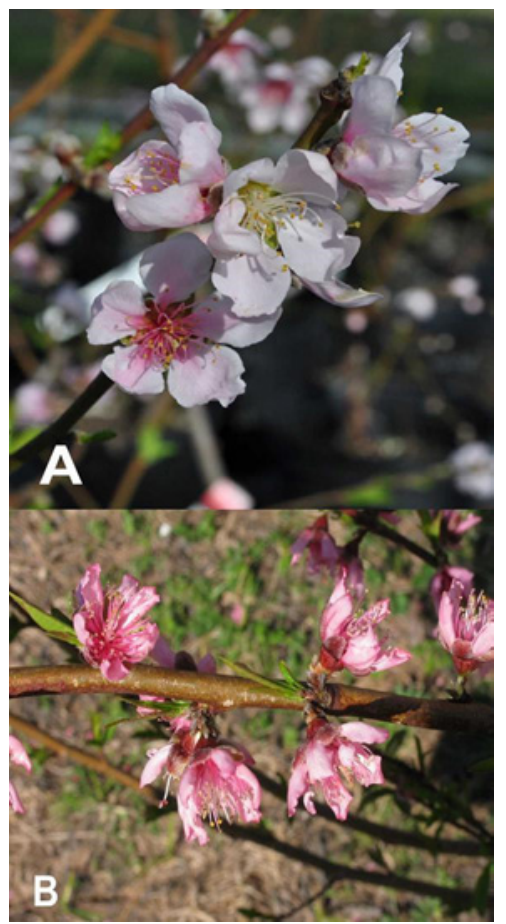

Figura 2. Flores de durazno vistosas (A) y no-vistosas (B). 


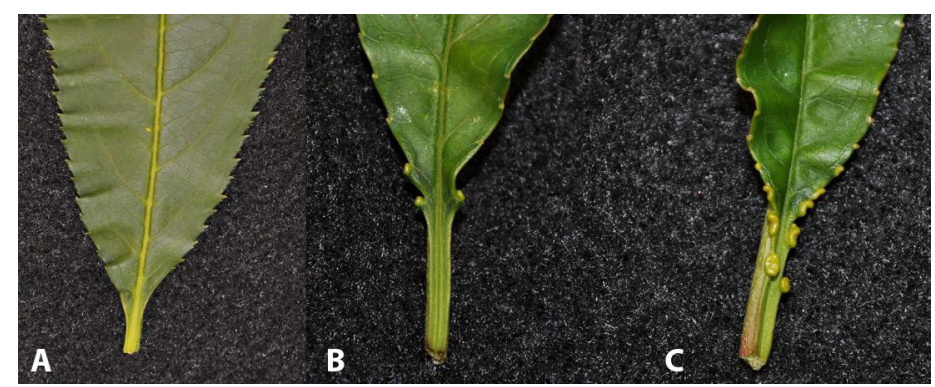

Figura 3. Glándulas de las hojas de durazno: no-glandular (A), globosa (B) y reniforme (C).

\section{Pulpa del durazno y descripción del hueso}

Los duraznos están típicamente disponibles en dos tipos diferentes de pulpa, la pulpa fundente y la no-fundente. Los duraznos de pulpa fundente experimentan un rápido ablandamiento de la carne a medida que la fruta madura. Históricamente, este tipo de fruta se ha utilizado para la producción de fruta fresca. Los duraznos de pulpa nofundente se caracterizan por un fenotipo de carne firme que se suaviza lentamente. Los duraznos de pulpa no-fundente se habían usado principalmente para procesamiento; sin embargo, las mejoras en el sabor y la textura a través del cultivo en la Universidad de Florida y en otros lugares han dado como resultado duraznos de pulpa no-fundente con características superiores de fruta para comer en fresco. Los cultivares de pulpa fundente son típicos y populares en puestos de frutas de granjas y en operaciones de coseche usted mismo (U-pick) en las cuales las frutas se cosechan después de madurar en el árbol. Normalmente, duraznos de pulpa fundente no se conservan muy bien durante el transporte ya que se acercan a la madurez fisiológica debido a su tendencia a magullarse con facilidad. Por lo tanto, cuando están destinados a la comercialización a distancia, los duraznos de pulpa fundente se cosechan mucho antes para soportar el transporte dentro de la cadena de comercialización. En esos casos, los niveles de azúcar (a menudo medidos como ${ }^{\circ}$ Brix), el sabor y el color no se desarrollarán tan bien como en las frutas maduradas en los árboles. La calidad de la fruta es una consideración importante para los consumidores a la hora de decidir si comprar de nuevo o no (Crisosto 2002); sin embargo, la calidad aceptable de la fruta puede ser difícil de lograr con cultivares de maduración temprana (Sharpe et al. 1954). El programa de UF se enfoca en el desarrollo de duraznos que no se derriten que son firmes incluso cuando están maduros.

Clingstone y freestone son dos términos que describen la tendencia relativa de la pulpa a adherirse al hueso. En un durazno clingstone, la carne se adhiere al hueso para que este no se pueda extraer fácilmente de la carne cuando la fruta se corta por la mitad. Todos los cultivares de durazno de pulpa no-fundente lanzados al mercado por la Universidad de Florida son clingstone o semi-clingstone (a medida que la fruta madura, la pulpa se vuelve más fácil de separar del hueso en duraznos que son semi-clingstone). La fruta de durazno con pulpa que se separa fácilmente del hueso se describe como freestone. Típicamente, los cultivares de durazno de pulpa fundente son semi-freestone o freestone; sin embargo, es posible tener un durazno clingstone de pulpa fundente. Si bien existe cierta variación en el grado de adherencia de la pulpa (por ejemplo, semi-freestone o semi-clingstone), no se dispone de cultivares de durazno freestone de pulpa no fundente.

Los duraznos son considerados como una fruta climatérica, lo que significa que la fruta puede continuar madurando después de la cosecha, aunque el nivel de azúcar y, por lo tanto, la dulzura percibida no aumentarán. A menudo, los duraznos que compran los consumidores pueden ser firmes, pero se suavizarán y desarrollarán más aroma cuando se coloquen en un mostrador o en un frutero. La fruta que se deja madurar en el árbol tiene una mejor calidad según muchos estándares de medición, pero particularmente la dulzura. El ambiente único de la Florida permite a los cultivadores comerciales cosechar cultivares de pulpa no fundente de 'maduración en árbol', que son firmes y de muy alta calidad.

\section{Descripción y clasificación de la fruta}

El tamaño de la fruta puede verse afectado por el potencial genético, la cantidad de fruta por árbol, las condiciones climáticas, las prácticas de manejo culturales y el tipo de suelo. El rendimiento de la fruta por árbol también puede verse afectado por la edad y el tamaño del árbol, y por la cantidad de raleo de la fruta luego que esta ha cuajado. Es especialmente difícil cultivar variedades que produzcan frutos grandes con un FDP corto porque cada etapa fenológica (división celular, endurecimiento del hueso, hinchamiento final de la fruta y elongación celular) en el desarrollo de la fruta requiere un cierto marco de tiempo. Los cultivares que tienen un FDP más largo tenderán a tener frutos más grandes porque estas etapas fenológicas pueden ocurrir durante períodos relativamente largos en comparación con los cultivares con FDP más cortos. Además, las temperaturas cálidas pueden comprimir estas etapas fenológicas, lo que también puede resultar en frutos más pequeños (López y DeJong 2007). El tamaño de la fruta de durazno en Florida se puede aumentar de mejor manera con un raleo adecuado en la etapa más temprana una vez haya pasado el peligro 
de las heladas y usando riego suplementario, especialmente durante el crecimiento final de la fruta.

Color de la fruta se refiere al color de fondo y al rubor (color rojo). Cuando la fruta de durazno madura, el color del fondo cambia de verde a amarillo. Los cambios en el color de fondo no se ven afectados por la posición de la fruta en el árbol o la exposición a la luz solar, por lo tanto, el equipo de cosecha puede utilizar el color de fondo para indicar la madurez de la fruta. Los cambios en el rubor, o el color rojo en la piel o la carne de la fruta, se ven afectados por la posición de la fruta en el dosel y la intercepción de la luz solar. Cuanto más expuesta al sol es una fruta, mayor es la intensidad de su rubor. Un alto porcentaje de color rojo (>70\%) y un color de fondo amarillo brillante son los más deseables para el atractivo y las ventas en los mercados de EE. UU. El porcentaje de color rojo es al menos el 50\% para muchos de los cultivares lanzados recientemente (Tabla 4). Si el color de fondo se vuelve difícil de ver debido al porcentaje alto de color rojo de la fruta, la aparición de un ligero ablandamiento en la punta de la fruta puede usarse para determinar el tiempo de cosecha correcto.

El atractivo total de la fruta está relacionado con la forma, el tamaño, el color de la fruta y el color dorado de la carne. La forma de la fruta, la firmeza, el sabor, el dorado de la carne y el atractivo general también se clasifican subjetivamente. La forma deseada para la fruta es de redondeada a oblonga, y las clasificaciones se reducen por el grado de puntas y suturas sobresalientes. Las frutas con alto aroma, acidez moderada y sabor dulce son las más deseables. No es deseable un alto grado de oscurecimiento de la carne a partir de cortes y moretones cuando las frutas están suaves y maduras. Las versiones más recientes del programa de reproducción de UF tienen poco o ningún oscurecimiento de la carne.

\section{Esfuerzos en el desarrollo de variedades de durazno y nectarina}

Los cultivares adaptados a la Florida han sido desarrollados por dos programas. El programa de fitomejoramiento de UF se centra en el desarrollo de cultivares con requisitos de enfriamiento que van desde aproximadamente 100 a 450 horas de frío. Un segundo programa de fitomejoramiento cooperativo se encuentra ubicado en Georgia en el Centro de Investigación y Educación Attapulgus de la Universidad de Georgia (UGA), en el que participan científicos de la Universidad de Florida (UF, Dr. José Chaparro), la Universidad de Georgia (Dr. Darío Chávez) y el Departamento de Agricultura de los Estados Unidos-Servicio de
Investigación Agrícola (USDA-ARS) en Byron, GA (Dr. Thomas Beckman) quienes se enfocan en el desarrollo de duraznos con requisitos de enfriamiento que varían de 350 a 650 horas frío.

\section{Patrones de durazno}

Todas las frutas de hueso cultivadas en Florida se injertan en patrones debido a la presencia del nematodo agallador del durazno (Meloidogyne floridensis). 'Flordaguard' es un patrón resistente a nematodos que actualmente se recomienda para producción comercial y viveros. Las distintivas hojas rojas de 'Flordaguard' permiten a los cultivadores identificarlo fácilmente en el vivero cuando surgen los retoños de raíz durante los primeros 2 a 3 años después de la siembra. El patrón 'Sharpe' también se puede usar como patrón resistente al nematodo agallador del durazno; sin embargo, ha sido criticado por el tamaño pequeño de la fruta. El patrón 'MP29' con resistencia al nematodo agallador del durazno y tolerancia a las enfermedades corta vida del durazno, y podredumbre de la raíz del roble, se ha lanzado para su uso en las áreas norte del estado. Se están probando otros patrones junto con el programa de fitomejoramiento de patrones de durazno del USDA-ARS en Byron, GA. Para obtener más información sobre patrones para fruta de hueso, consulte http://edis.ifas.ufl.edu/hs366.

\section{Cultivares comerciales de durazno y nectarina}

Uno de los principales objetivos del programa de fitomejoramiento de fruta de hueso de UF ha sido el desarrollo de variedades de duraznos de pulpa no-fundente y que puedan ser cosechados en árboles maduros. Los cultivares comerciales de duraznos de pulpa no-fundente que se han lanzado desde el programa de fitomejoramiento de la Universidad de Florida comienzan con el prefijo 'UF', es decir, 'UFO, 'UFBest', 'UFSharp', 'UFBeauty', 'UFGlo', 'UFSun', y 'UFOne' (Tabla 4). Asimismo, los cultivares de nectarina de pulpa no-fundente 'UFQueen' y 'UFRoyal' han sido lanzados del programa de la UF. Para los productores de durazno en el norte de Florida y el sur de Georgia, los esfuerzos del programa de fitomejoramiento cooperativo de la Universidad de Florida, la Universidad de Georgia y el USDA-ARS mencionado anteriormente, ha lanzado 'GulfAtlas', 'Gulfsnow', 'Gulfprince,' 'Gulfking,' 'Gulfcrest' y 'Gulfcrimson', los cuales requieren una mayor acumulación de unidades de enfriamiento (350-525 horas frío). Hoy en día, estos y otros cultivares lanzados por el Programa de fitomejoramiento de fruta de hueso de la UF se cultivan en Australia, Egipto, Marruecos, Sudáfrica y otros lugares alrededor del mundo. 


\section{Descripción de cultivares}

Una de las decisiones más importantes que toma un productor es garantizar que un cultivar seleccionado se adapte a un sitio en particular. Se recomiendan cultivares de durazno específicos destinados a la producción comercial para cada área a fin de garantizar que los requisitos de las unidades de enfriamiento de los cultivares se cumplan en la mayoría de los años. Se pueden crecer cultivares con mayores requisitos de unidades de enfriamiento, pero sus unidades de enfriamiento requeridas no se acumularán cada año, lo que resultará en un cultivo inconsistente.

A continuación, se enumeran los cultivares recomendados de durazno, nectarina y ciruela para la producción a escala comercial, con el objetivo de aprovechar una ventana de mercado temprana (abril a mayo).

\section{Florida Norte y Florida Norte-Central 'FLORDABEST'-250 UNIDADES DE FRÍO}

El cultivar 'Flordabest' se lanzó y patentó en 2009 y tiene un FDP de 82 días desde la cuajada hasta la cosecha. La fruta desarrolla un $90 \%-100 \%$ de rubor, haciéndola muy atractiva. La fruta es grande y tiene una pulpa fundente pero uniformemente firme de color amarillo y hueso del tipo semi-clingstone. La fruta madura entre 7 a 10 días antes que la variedad de durazno estándar 'TropicBeauty' en Gainesville, Florida. Se recomienda para prueba en Gainesville y al sur de la autopista interestatal 4 (Figura 4).

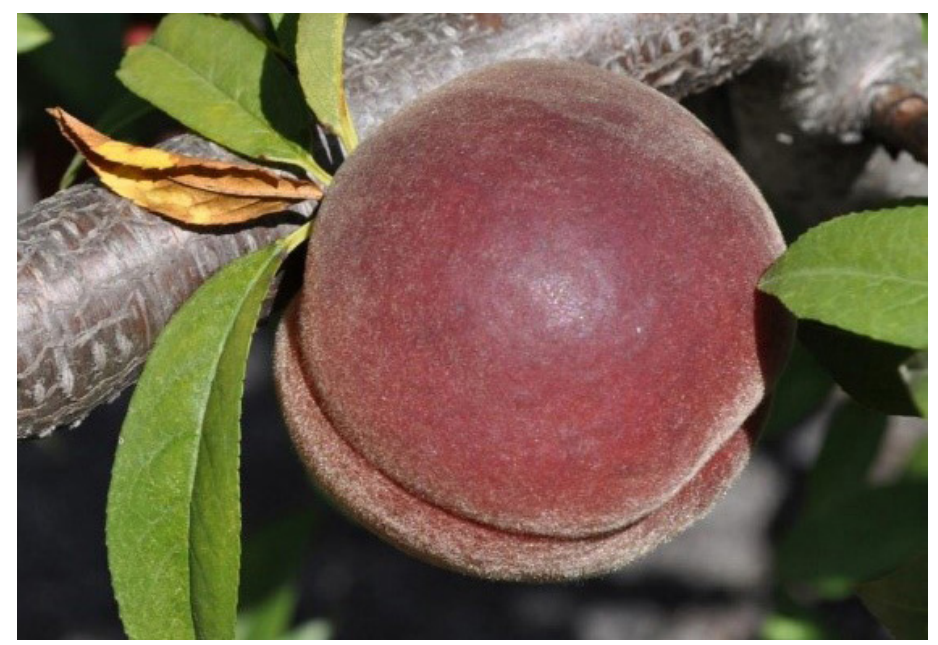

Figura 4. 'Flordabest'

\section{‘UFO'-250 UNIDADES DE FRÍO}

'UFO' es un melocotón fenotipo de carne no fundida con una forma única de rosquilla. Fue patentado en 2002 y produce árboles grandes y vigorosos con un hábito de crecimiento semi-vertical. 'UFO' produce cargas moderadamente pesadas de frutos grandes y firmes con pulpa amarilla y hueso del tipo semi-freestone con un FDP de 95 días. La piel desarrolla un 50\%-70\% de rubor. Este cultivar es particularmente susceptible al etileno que se libera durante la poda de invierno, lo que puede resultar en un aborto significativo de yemas florales. Por lo tanto, la poda solo se recomienda durante el período de verano (Figura 5).

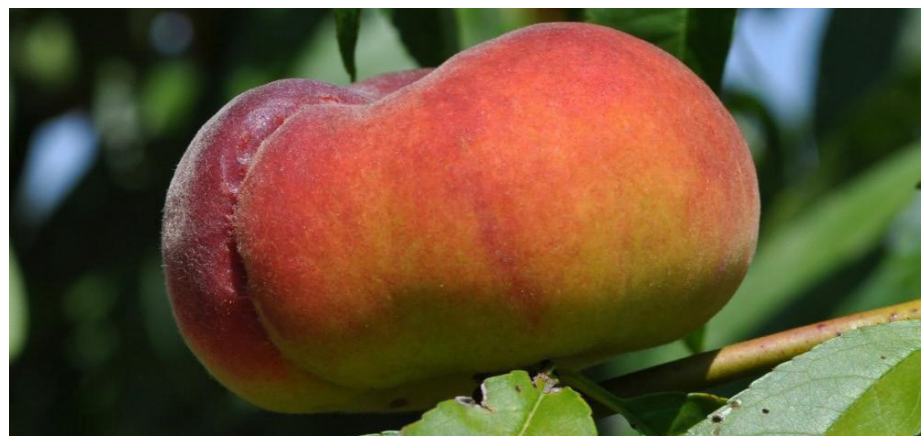

Figura 5. 'UFO'

\section{“GULFKING' - 350 UNIDADES DE FRÍO}

'Gulfking' es un cultivar de pulpa no fundente que fue lanzado y patentado por el programa de fitomejoramiento conjunto entre UF, UGA y USDA-ARS en el 2004 (Krewer et al. 2005). La fruta tiene un color excepcional, con $80 \%-90 \%$ de piel roja con rayas sobre un color de fondo amarillo intenso. La fruta es muy firme con pulpa amarilla y es del tipo clingstone. El FDP es 77 días y la fruta se desarrolla en buen tamaño, forma y color en el norte de Florida (Figura 6).

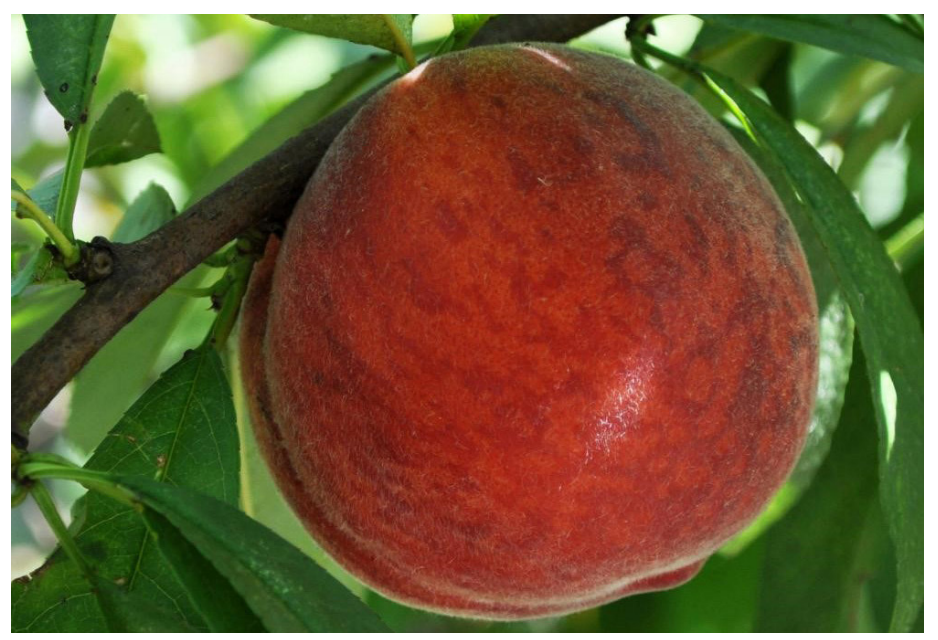

Figura 6. 'Gulfking'

\section{'GULFSNOW'-400 UNIDADES DE FRÍO}

'Gulfsnow' es un lanzamiento conjunto entre la Universidad de Florida, la Universidad de Georgia y el programa de reproducción USDA-ARS en el 2012. Los árboles de 'Gulfsnow' son vigorosos y semi-dispersos, y producen frutos blancos de pulpa no fundente. La fruta 'Gulfsnow' es grande, redonda y atractiva, con un $50 \%-60 \%$ de rubor sobre un fondo crema. El fruto es del tipo clingstone, con hueso rojo de tamaño mediano y un FDP de 110 días (Figura 7). 


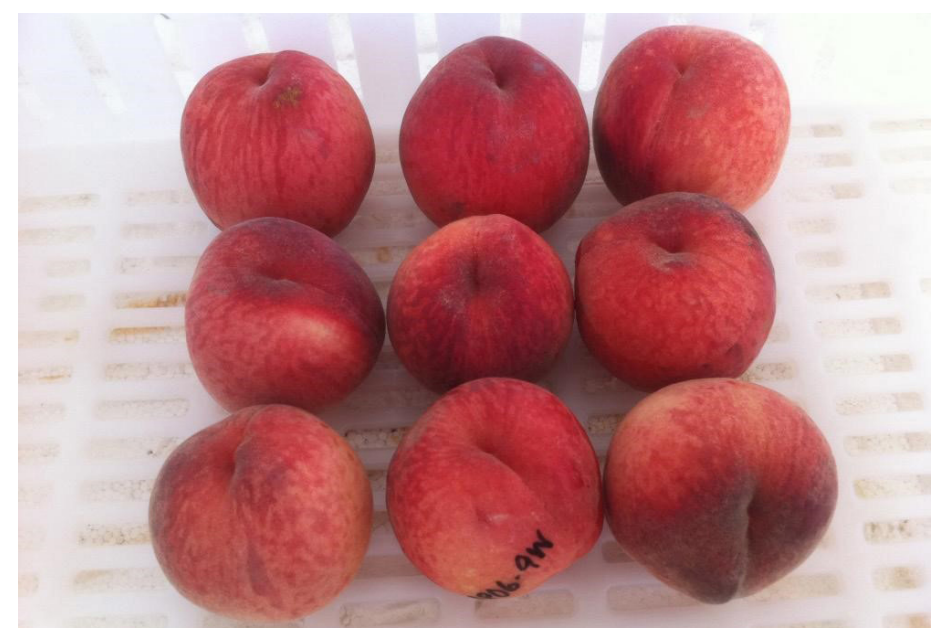

Figura 7. 'Gulfsnow'

\section{“GULFCRIMSON”-400 UNIDADES DE FRÍO}

'Gulfcrimson' es el tercero de una serie de cultivares lanzados y patentados por el programa de fitomejoramiento de fruta de hueso en colaboración entre UF, UGA y USDAARS, específicamente en 2009 (Krewer et al. 2008). La fruta 'Gulfcrimson' es grande para un cultivar de maduración temprana y tiene un color de fondo amarillo con $80 \%-90 \%$ de piel roja. 'Gulfcrimson' madura con el cultivar estándar de melocotón 'JuneGold' en Attapulgus, Georgia, con un FDP de 95 días y un cultivo muy consistente, lo que lo convierte en un buen sustituto para 'JuneGold' en la mitad de la temporada. También produce cultivos confiables en el norte del estado de la Florida (Figura 8).

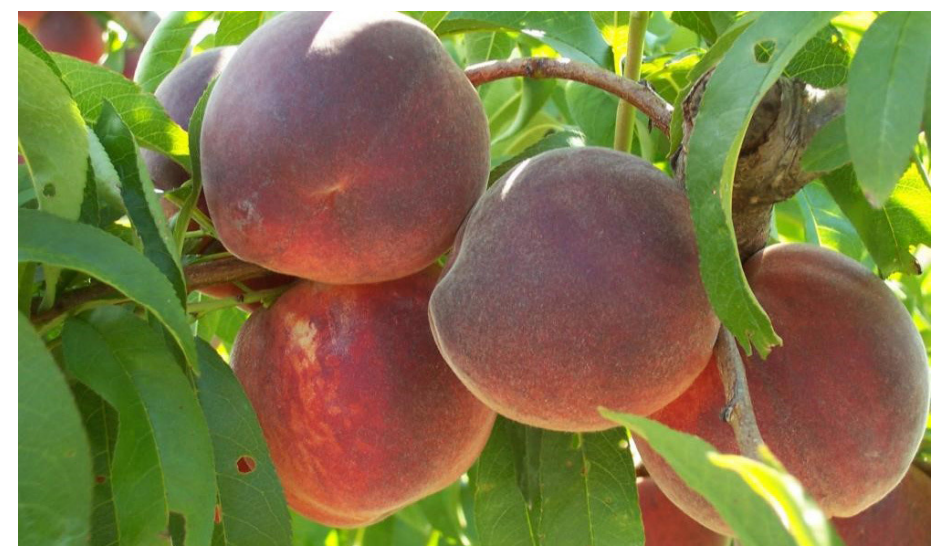

Figura 8. 'Gulfcrimson'

\section{‘UFGLO’-400 UNIDADES DE FRÍO}

'UFGlo' es un melocotón blanco de pulpa no fundente que se lanzó en 2009. La fruta 'UFGlo' es grande, desarrolla un $80 \%-90 \%$ de rubor en toda la fruta y es del tipo clingstone. El FDP es de 80 a 85 días. 'UFGlo' madura en áreas donde el cultivar estándar 'Flordaking' funciona bien, y complementa los duraznos 'UFSharp' en el centro-norte de Florida. Produce cultivos consistentes con buenos rendimientos en el norte de Florida (Figura 9).

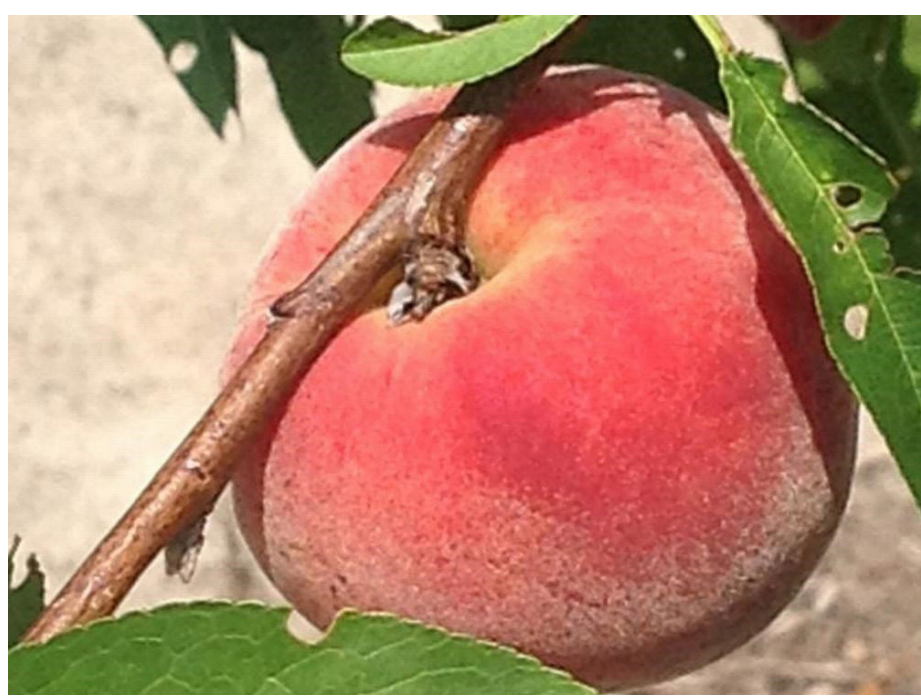

Figura 9. 'UFGlo'

\section{'GULFATLAS' - 400 UNIDADES DE FRÍO}

'GulfAtlas' es un lanzamiento de 2014 de la UF, UGA y el programa de reproducción conjunta USDA-ARS. Es una variedad de final de temporada, con un FDP de 120 días. La fruta es de pulpa no fundente, de tipo clingstone y una carne de color amarillo brillante. La fruta es muy grande, redonda y madura aproximadamente 3 semanas después de 'Gulfcrimson'. La fruta madura tiene un $75 \%$ de rubor, con algo de pigmentación roja en la pulpa inmediatamente debajo de la cáscara. Los árboles son vigorosos y semiesparcidos, con pocos nodos ciegos y buen establecimiento del fruto. 'GulfAtlas' está adapta a un área entre el sur de Attapulgus, GA, a Gainesville, FL (Figura 10).

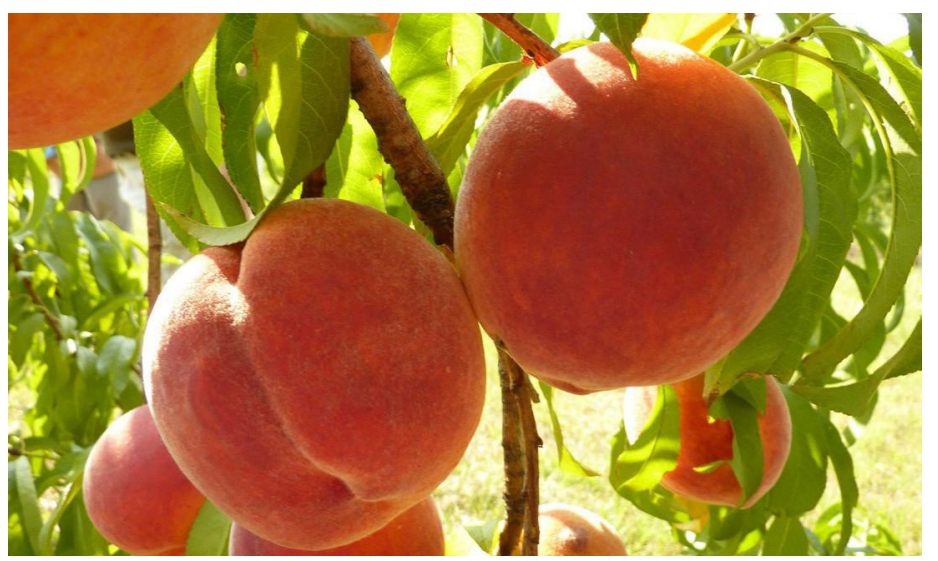

Figura 10. 'GulfAtlas'

Credits: USDA-ARS

\section{'GULFCREST'-525 UNIDADES DE FRÍO}

'Gulfcrest' es un lanzamiento de 2004 de la UF, UGA y el programa de reproducción conjunto con el USDA-ARS. Tiene un FDP de 62 a 75 días y tiene una pulpa no fundente con un hueso clingstone. La fruta madura de la variedad 'Gulfcrest' tiene un 90\%-95\% de color rojo sobre un color de fondo amarillo intenso a naranja y se madura a 
principios o a mediados de mayo en el sur de Georgia. El fruto de 'Gulfcrest' puede ser de tamaño variable en el árbol $y$ puede tener un crecimiento con muchas ramas pequeñas. La variedad 'Gulfcrest' está adaptada al extremo norte de Florida y al sur de Georgia (Figura 11).

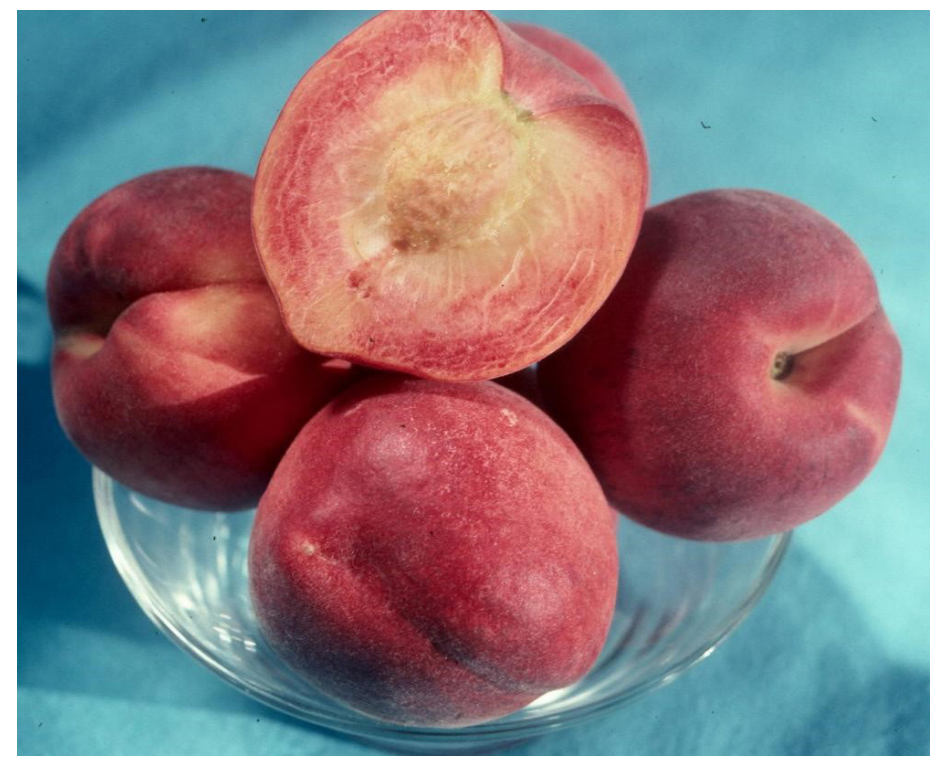

Figura 11.'Gulfcrest'

Credits: USDA-ARS

\section{Cultivares de Nectarina}

\section{'SUNBEST'-225 UNIDADES DE FRÍO}

'Sunbest' lanzado en 2001, es un cultivar de nectarina patentado con pulpa amarilla del tipo fundente, y un hueso semi-clingstone. Desarrolla un $90 \%-100 \%$ de rubor rojo brillante sobre un color de fondo amarillo y tiene un FDP de 85-90 días. 'Sunbest' madura a principios de mayo (Gainesville, FL), unos 3 días antes del cultivar estándar de nectarina 'Sunraycer'. Es superior y un buen reemplazo para la nectarina 'Sunraycer' (Figura 12).

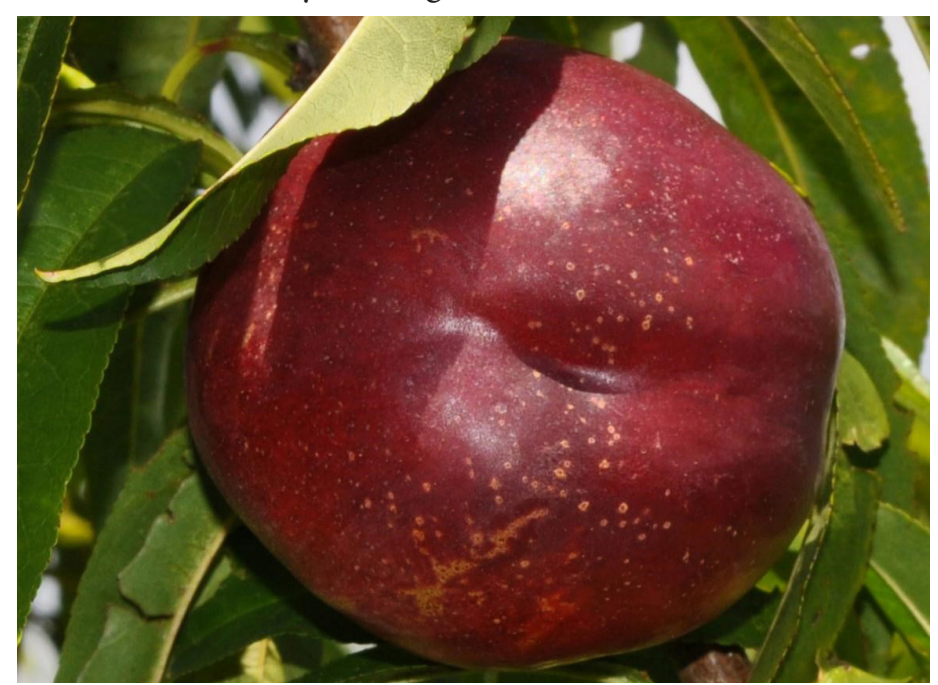

Figura 12.'Sunbest'

\section{'UFROYAL'-250 UNIDADES DE FRÍO}

'UFRoyal' es una nectarina de pulpa amarilla no fundente, con un FDP de 85 días. La fruta 'UFRoyal' es grande, con una piel 100\% roja, y un hueso semi-clingstone. Las frutas son ovaladas simétricamente y maduran aproximadamente 1 semana antes de 'UFQueen' (abajo) a principios de mayo (Gainesville, FL). La fruta 'UFRoyal' tiene una excelente firmeza y sabor, con un excelente potencial de envío (Figura 13).

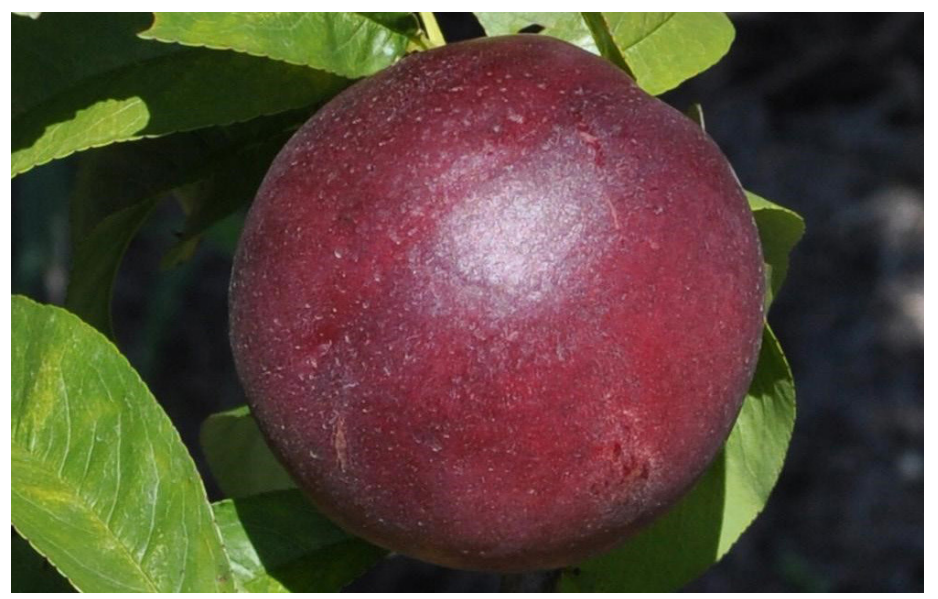

Figura 13. 'UFRoyal'

\section{'UFQUEEN'—250 UNIDADES DE FRÍO}

'UFQueen' es una variedad que habitualmente produce fruta grande y temprana en el centro norte de Florida, con un FDP de 95 días. Los árboles 'UFQueen' son semiverticales y se pueden podar fácilmente en un sistema de base abierta. La fruta tiene una pulpa no fundente de color amarillo y con hueso clingstone. El fruto es ligeramente ovalado con una ligera punta y desarrolla $80 \%-100 \%$ de piel roja sobre un fondo amarillo. La fruta 'UFQueen' madura aproximadamente 1 semana después del cultivar estándar de nectarina 'Sunraycer', a mediados de mayo en Gainesville, Florida (Figura 14).

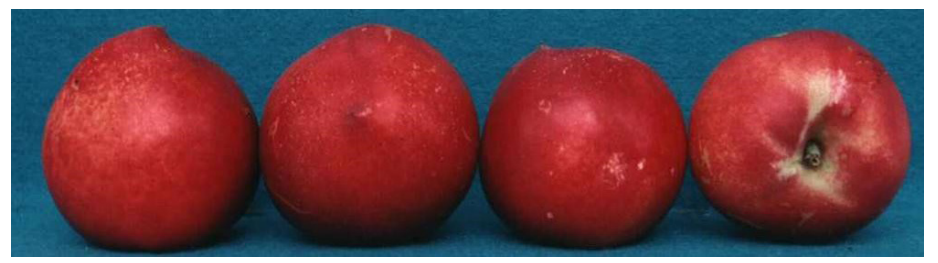

Figura 14. 'UFQueen'

\section{Florida Central y Sur Central ‘UFSUN’-100 UNIDADES DE FRÍO}

'UFSun' es un cultivar de durazno de pulpa no fundente lanzado en 2004 (Rouse et al. 2004). Los árboles 'UFSun' producen grandes cosechas anuales en la temporada temprana, fruta mediana, con pulpa amarilla y hueso clingstone. Las frutas 'UFSun' son uniformemente simétricas y desarrollan una piel roja con un 50\%-60\% de rayas 
rojas más oscuras. La fruta de 'UFSun' madura al tiempo con la de la variedad de durazno estándar 'Flordaprince' en Immokalee y Gainesville, Florida, con un FDP de 80 días (Figura 15).

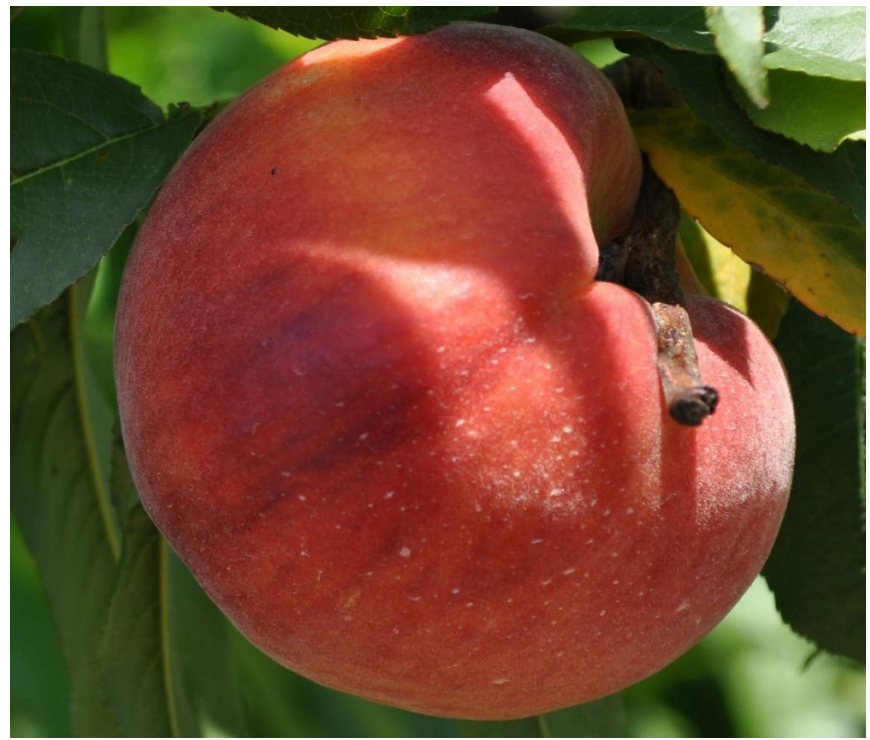

Figura 15. 'UFSun'

\section{‘UFBEST'-100 UNIDADES DE FRÍO}

'UFBest' lanzado por el programa de fitomejoramiento de la UF en 2012, este cultivar de pulpa no fundente produce grandes cosechas anuales de fruta grande. La fruta 'UFBest' desarrolla un $95 \%-100 \%$ de piel roja sobre un color de fondo amarillo, y la pulpa es amarilla con hueso clingstone. 'UFBest' madura una semana antes que 'UFSun' (mediados de abril) en Gainesville, Florida, con un FDP de 85 días (Figura 16).

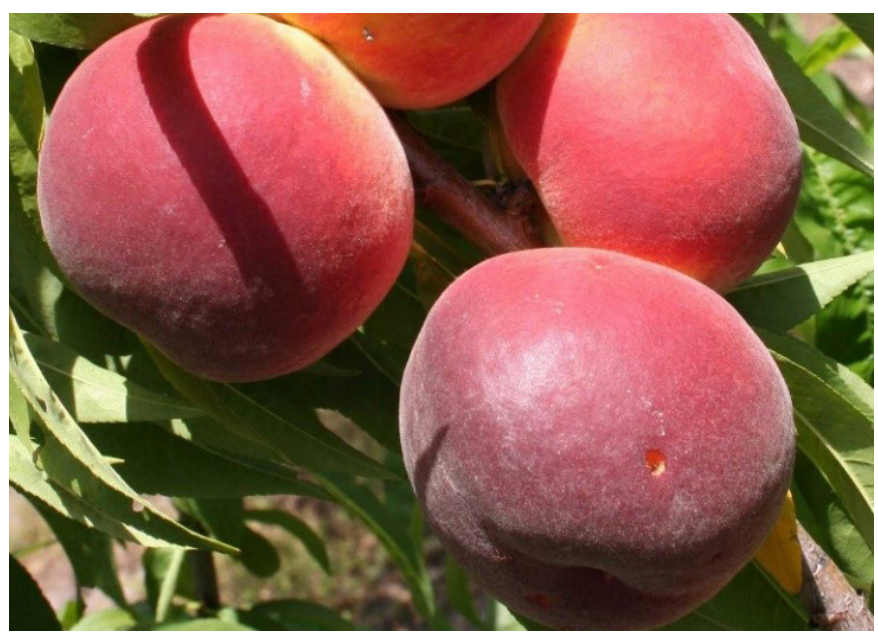

Figura 16. 'UFBest'

\section{'TROPICBEAUTY'-150 UNIDADES DE FRÍO}

'TropicBeauty' es un cultivar no patentado lanzado en conjunto por la Universidad de Florida y Texas A\&M en 1989. Las frutas de tamaño medio y semi-freestone tienen una pulpa amarilla fundente y desarrollan un $70 \%$ de rubor sobre un fondo amarillo. 'TropicBeauty' madura entre 'UFSun' y 'UFOne' y tiene un FDP de 89 días (Figura 17).

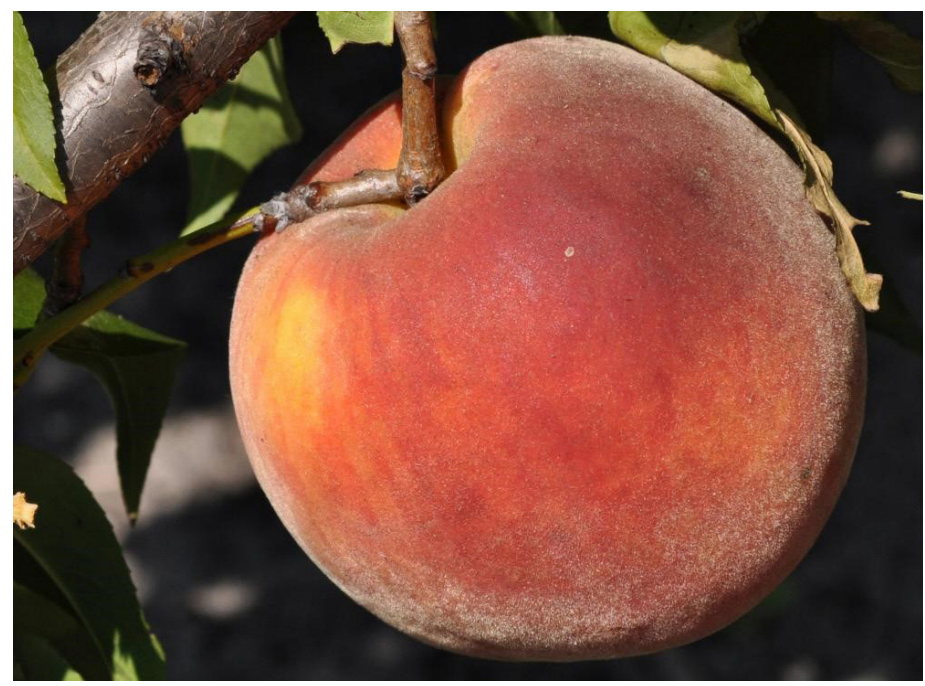

Figura 17. 'TropicBeauty'

\section{‘UFGEM'-175 UNIDADES DE FRÍO}

'UFGem' fue lanzado en 2013 y es un buen candidato para la parte norte del centro de Florida. Es una variedad comercial con un rubor cercano al $100 \%$, un tamaño promedio de fruta de 2.5 pulgadas de diámetro y forma simétrica. Es un durazno clingstone con pulpa no fundente, amarilla y de textura firme. El FDP promedio es de 83 días y da buen fruto cuando las temperaturas mínimas nocturnas son superiores a $57^{\circ} \mathrm{F}\left(14^{\circ} \mathrm{C}\right)$ (Figura 18$)$.

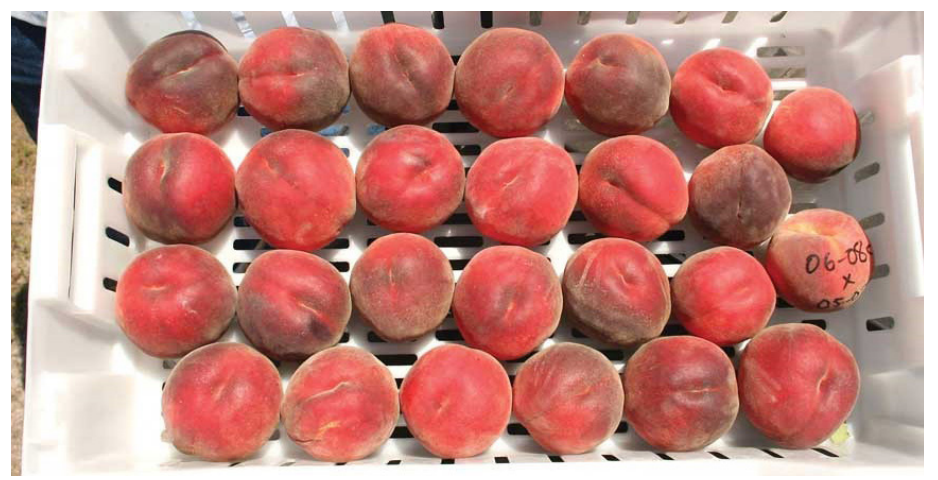

Figura 18. 'UFGem'

\section{'UFBEAUTY'-200 UNIDADES DE FRÍO}

'UFBeauty' es un cultivar de melocotón lanzado en 2002 con frutas de pulpa no fundente, hueso clingstone y una forma muy simétrica. La pulpa de la fruta 'UFBeauty' es amarilla y muy firme, y el color de la piel es casi 100\% rojo, con rayas rojas más oscuras. 'UFBeauty' madura de 3 a 4 días después de 'UFGold' en Gainesville, Florida, con un FDP de 82 días. El cultivo de 'UFBeauty' no ha sido confiable en el sur de la Florida cuando las temperaturas nocturnas durante el período de floración son superiores a los $57^{\circ} \mathrm{F}\left(14^{\circ} \mathrm{C}\right.$, Figura 19). 


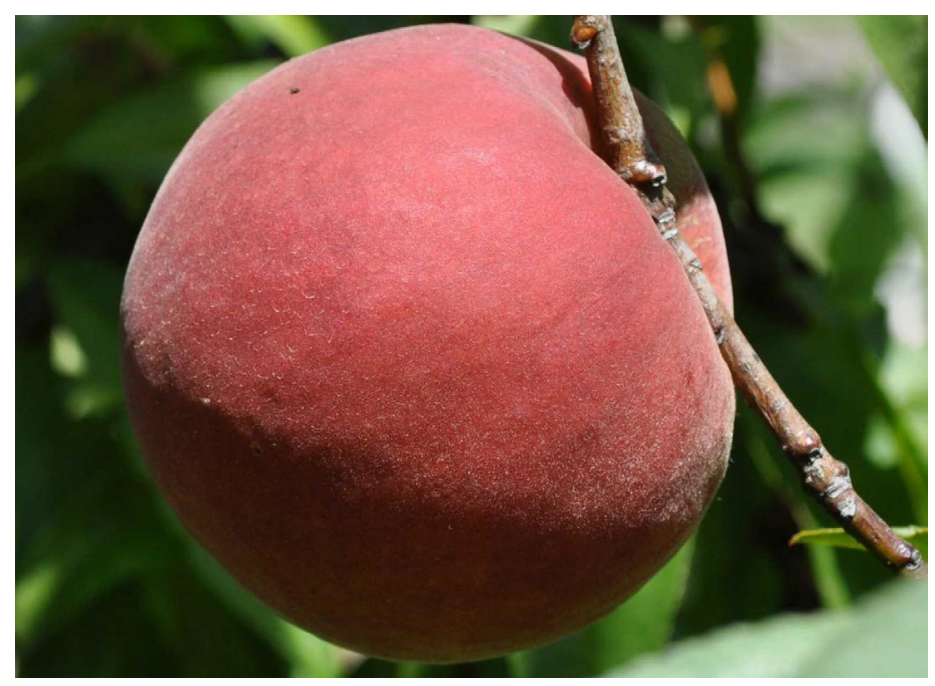

Figura 19. 'UFBeauty'

\section{‘UFONE’ - 250 UNIDADES DE FRÍO}

'UFOne' es un cultivar de pulpa no fundente lanzado por UF en 2008. La fruta 'UFOne' es medianamente grande, y los árboles regularmente producen grandes cosechas de fruta comercializable. La fruta 'UFOne' es muy firme, con pulpa amarilla y hueso semi-clingstone y desarrolla un $40 \%$ de rubor rojo sobre un fondo amarillo. La fruta 'UFOne' tiene un FDP bastante largo de 95 días y madura con 'UFBeauty' (principios de mayo) en Gainesville, Florida (Figura 20).

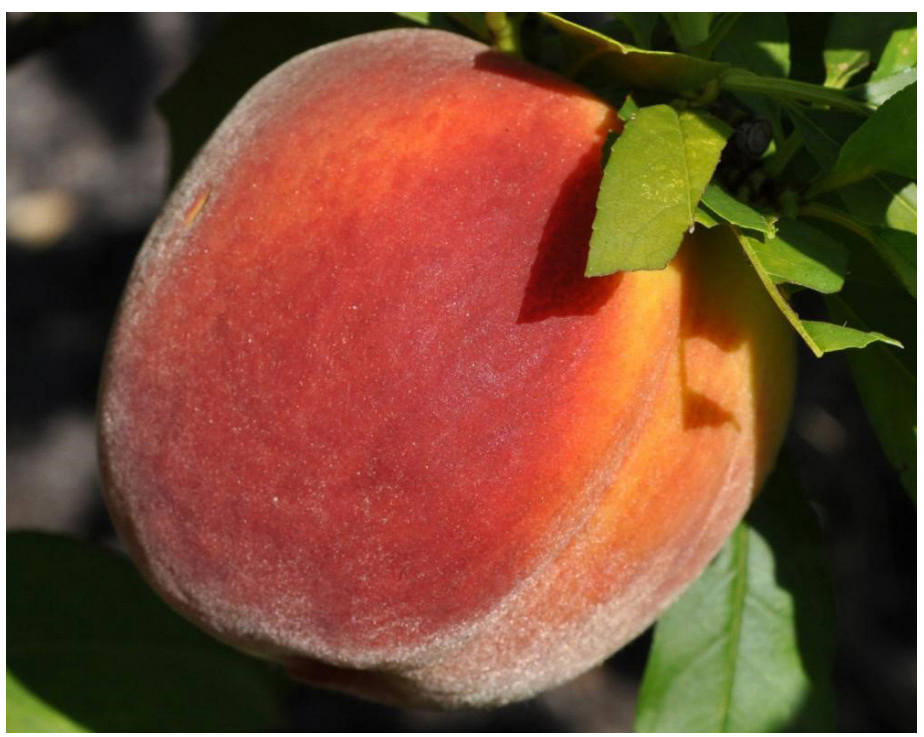

Figura 20. 'UFOne'

\section{Florida Norte y Norte Central ‘UF2000”-300 UNIDADES DE FRÍO}

'UF2000' es un durazno de color amarillo de pulpa no fundente, hueso clingstone lanzado en 2000. Los árboles son muy vigorosos con un hábito de crecimiento semiextendido y producen cosechas anuales substanciales de frutos moderadamente grandes. La fruta 'UF2000' tiene una forma simétrica y desarrolla un 50\%-70\% de piel roja sólida sobre un fondo amarillo. La fruta 'UF2000' madura a mediados de la temporada, y la cosecha se produce entre 15 y 18 días antes de 'UFGold' a mediados de mayo en Gainesville, Florida (Figura 21).

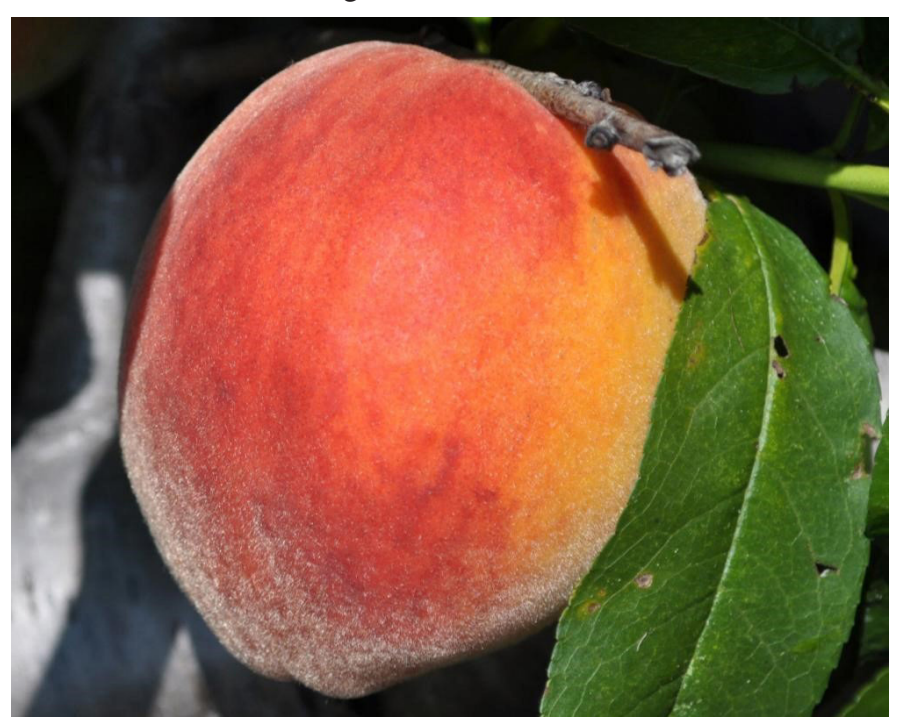

Figura 21. 'UF2000'

\section{‘UFBLAZE'-300 UNIDADES DE FRÍO}

'UFBlaze' es una variedad de durazno de pulpa no fundente lanzada en 2002. Los árboles son muy vigorosos y de naturaleza semi-extendida. Los árboles 'UFBlaze' producen grandes cultivos anuales de fruta grande, atractiva y de maduración temprana, con una piel de color rojo brillante sobre un $80 \%-90 \%$ de fondo de color amarillo-naranja brillante y pulpa amarilla. Las frutas son uniformes y simétricas, y maduran aproximadamente de 7 a 10 días después de 'UFGold' a principios o mediados de mayo en Gainesville, Florida, con un FDP de 83 días (Figura 22).

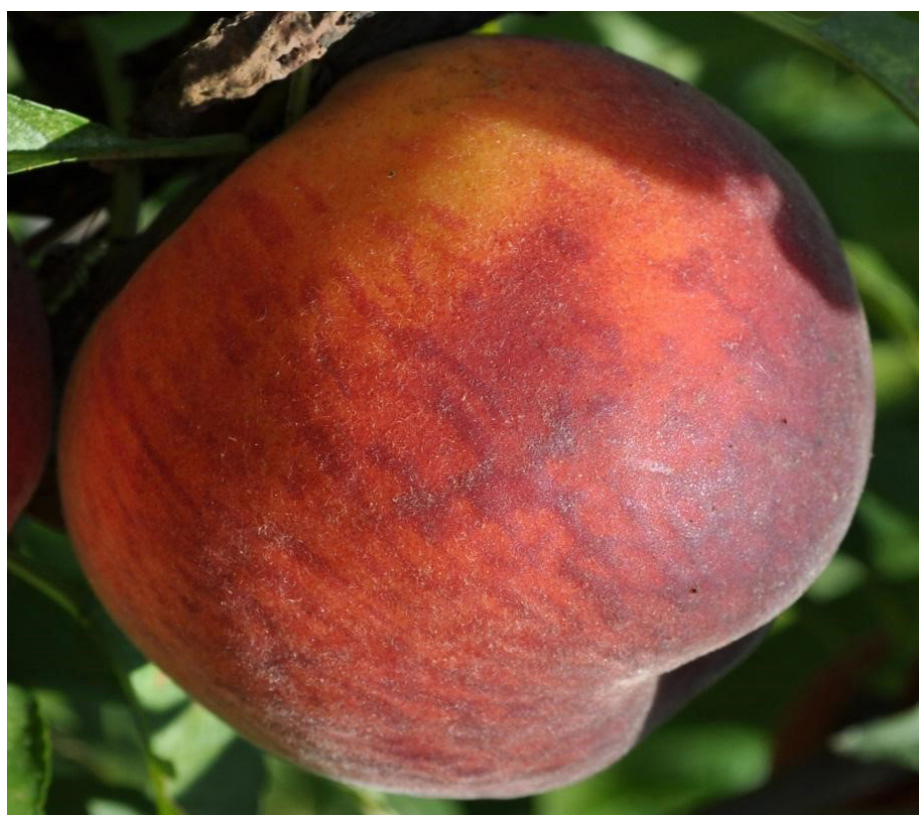

Figura 22. 'UFBlaze' 


\section{‘FLORDADAWN'-300 UNIDADES DE FRÍO}

'Flordadawn' es una variedad de durazno no patentada de pulpa fundente lanzada en 1989. Los árboles 'Flordadawn' son vigorosos y producen grandes cantidades de flores con fructificación moderadamente alta. El período de floración de 'Flordadawn' es extendido, lo que puede ayudar con la producción de fruta durante las heladas al inicio de la primavera. El FDP de 'Flordadawn' es de 60 días, que es el más corto de cualquier variedad de durazno con nombre. La fruta de 'Flordadawn' desarrolla un $80 \%$ de rubor rojo y tiene pulpa amarilla con un hueso semi-clingstone. Sin embargo, las cargas de cultivo ligeras han dado como resultado una incidencia de hueso dividido de hasta $50 \%$. 'Flordadawn' a menudo se puede encontrar en grandes tiendas y viveros para plantaciones de patio trasero (Figura 23).

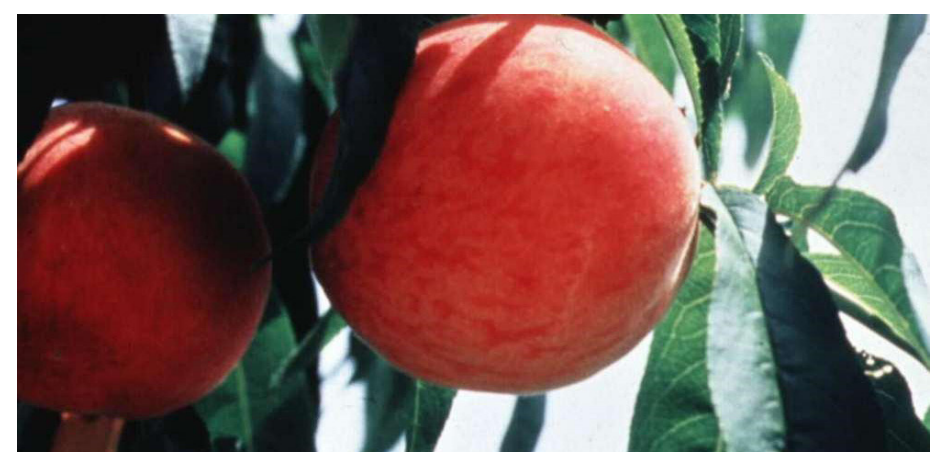

Figura 23. 'Flordadawn'

\section{‘UFSHARP'—325 UNIDADES DE FRÍO}

'UFSharp' es una variedad patentada de durazno de pulpa no fundente y de tipo clingstone lanzada en 2006. Los árboles 'UFSharp' son vigorosos, de naturaleza semi-dispersa y productivos. La fruta 'UFSharp' desarrolla un rubor rojo del $60 \%$ sobre un color de fondo amarillo intenso a anaranjado. 'UFSharp' tiene un cultivo confiable con excelente tamaño, forma y firmeza del fruto, y un FDP de 105 días (Figura 24).

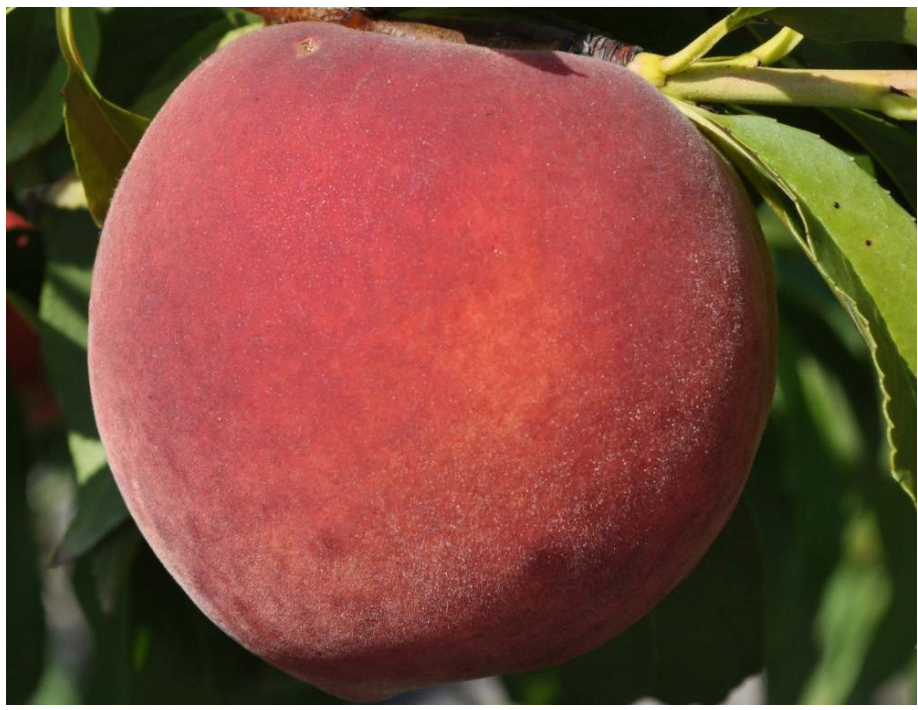

Figura 24. 'UFSharp'

\section{'FLORDACREST'-350 UNIDADES DE FRÍO}

'Flordacrest' es un cultivar de durazno semi-clingstone de pulpa fundente lanzado en 1988. Los árboles de 'Flordacrest' son vigorosos y tienen un hábito de crecimiento esparcido. La fruta de 'Flordacrest' tiene pulpa amarilla y desarrolla un $60 \%-80 \%$ de rubor rojo sobre un color de fondo amarillo brillante. Es el mejor durazno de pulpa fundente disponible actualmente para el norte de Florida. Madura después de 'Flordaking' en el norte de Florida, a principios de mayo en Gainesville, Florida, con un FDP de 75 días (Figura 25).

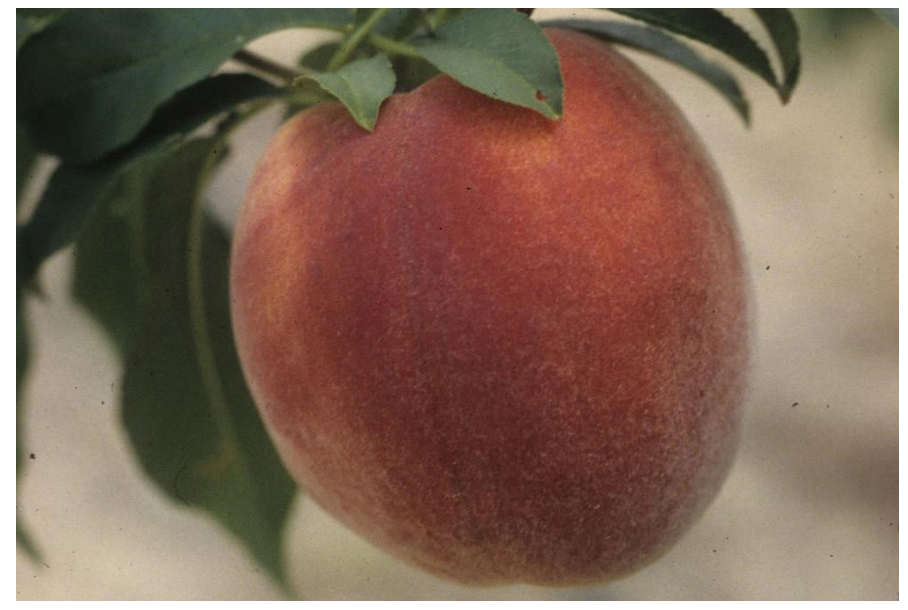

Figure 25. 'Flordacrest'

\section{'GULFPRINCE'-400 UNIDADES DE FRÍO}

'Gulfprince' fue lanzado conjuntamente por la Universidad de Florida, la Universidad de Georgia y el USDA-ARS en 2002. Los árboles de 'Gulfprince' son grandes y vigorosos con un hábito de crecimiento esparcido. Los frutos de 'Gulfprince' son uniformes y simétricos y desarrollan un $45 \%-55 \%$ de piel roja sólida. La fruta tiene pulpa amarilla no fundente con hueso clingstone. La fruta de 'Gulfprince' ha exhibido un ligero ennegrecimiento debido a la oxidación de la fruta suave y madura. El FDP es de 110 días (Figura 26).

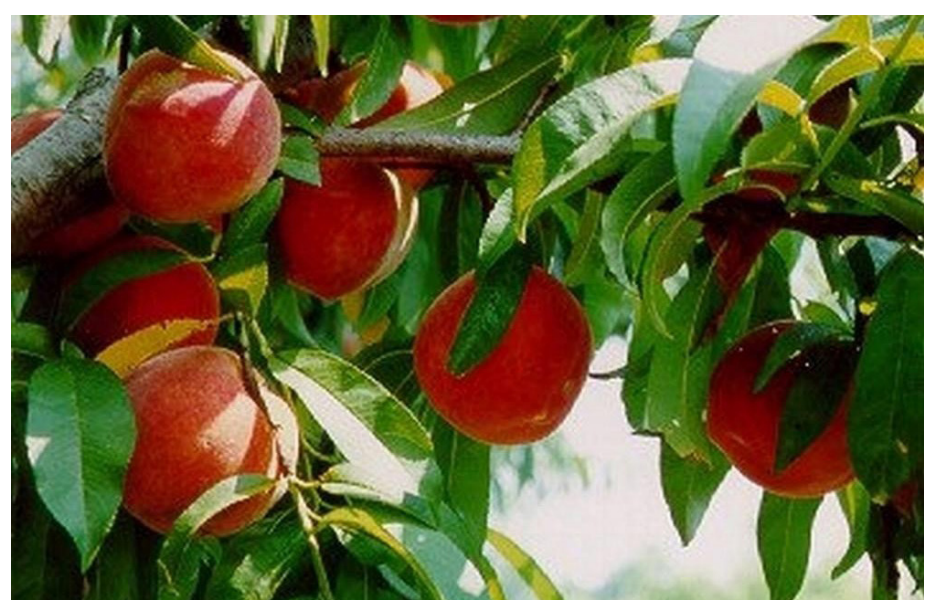

Figura 26. 'Gulfprince' Credits: USDA-ARS 


\section{‘FLORDAKING' — 450 UNIDADES DE FRÍO}

'Flordaking' es un cultivar antiguo lanzado en 1978. No está patentado y es una buena selección para la producción en patios, con fruta grande para un cultivar de durazno de mitad de temporada y resistencia moderada a la mancha bacteriana de las hojas. El fruto de 'Flordaking' tiene pulpa amarilla, de pulpa fundente y hueso clingstone. La fruta 'Flordaking' desarrolla un rubor rojo del 70\% sobre un color de fondo amarillo. 'Flordaking' tiene un FDP de 65 a 70 días y madura a principios de mayo (Gainesville, FL). Una desventaja de la fruta 'Flordaking' es la alta incidencia de hueso dividido cuando las cargas de cultivo son bajas (Figura 27).

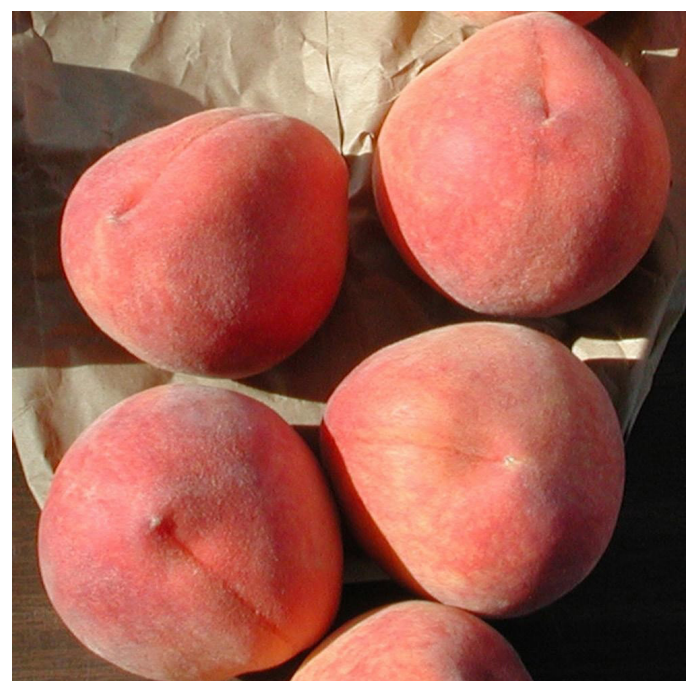

Figura 27. 'Flordaking'

\section{Cultivares de Nectarina 'SUNRAYCER'—275 UNIDADES DE FRÍO}

'Sunraycer' es un cultivar de nectarina de carne fundida no patentado lanzado en 1993. Los árboles son vigorosos y semi-esparcidos y responden bien a los sistemas de poda de centro abierto. 'Sunraycer' produce fruta grande, semiclingstone con buena resistencia a la mancha bacteriana. La fruta 'Sunraycer' desarrolla un rubor rojo brillante del $80 \%-100 \%$ sobre un color amarillo brillante y es ovalada sin puntas afiladas o protuberancias de sutura. 'Sunraycer' tiene un FDP de 85 días y madura a principios de mayo en Gainesville, Florida (Figura 28).

\section{'SUNBEST'-225 UNIDADES DE FRÍO}

'Sunbest' es un cultivar de nectarina patentado de pulpa fundente lanzado en 2001. Los árboles 'Sunbest' son semi-verticales y vigorosos, y responden bien a los sistemas de poda de centro abierto. La fruta 'Sunbest' desarrolla un rubor rojo brillante del $90 \%-100 \%$ sobre un color de fondo amarillo, es semi-freestone y resiste bien la mancha bacteriana. Se pretende que 'Sunbest' sea el reemplazo a la nectarina 'Sunraycer' debido a su fruta más grande y atractiva. 'Sunbest' tiene un FDP de 85-90 días, y la fruta madura aproximadamente 3 días antes de la nectarina 'Sunraycer' y el durazno 'Flordaglo' en Gainesville, Florida (Figura 29).

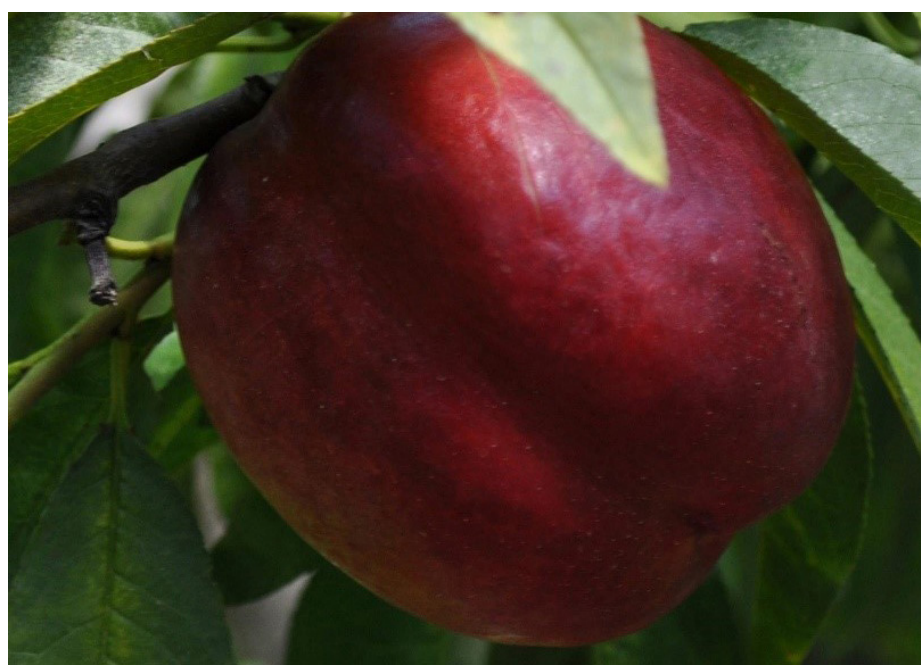

Figura 28. 'Sunraycer'

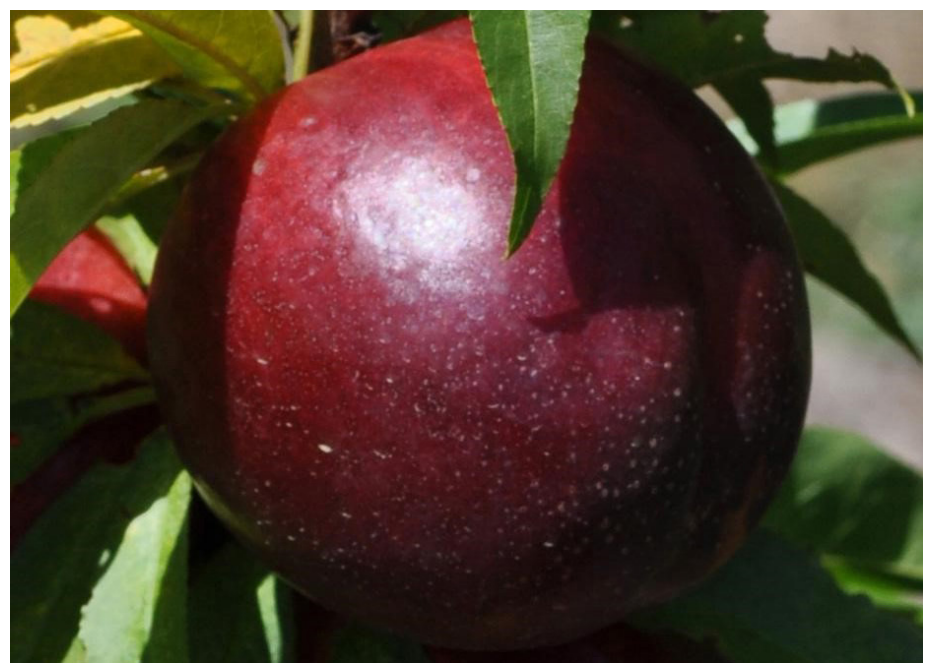

Figura 29. 'Sunbest'

\section{'SUNMIST'-300 UNIDADES DE FRÍO}

'Sunmist' es un cultivar de nectarina patentado de pulpa fundente lanzado en 1994. Los árboles 'Sunmist' son muy vigorosos y tienen un hábito de crecimiento esparcido. La fruta de 'Sunmist' tiene pulpa blanca, es semi-freestone y es grande para un cultivar de maduración temprana. Las frutas desarrollan casi un $100 \%$ de rubor rojo y son uniformemente simétricas. Los árboles y frutos 'Sunmist' son altamente resistentes a la mancha bacteriana. El FDP es de 85 días y la fruta madura a principios de mayo en Gainesville, Florida (Figura 30). 


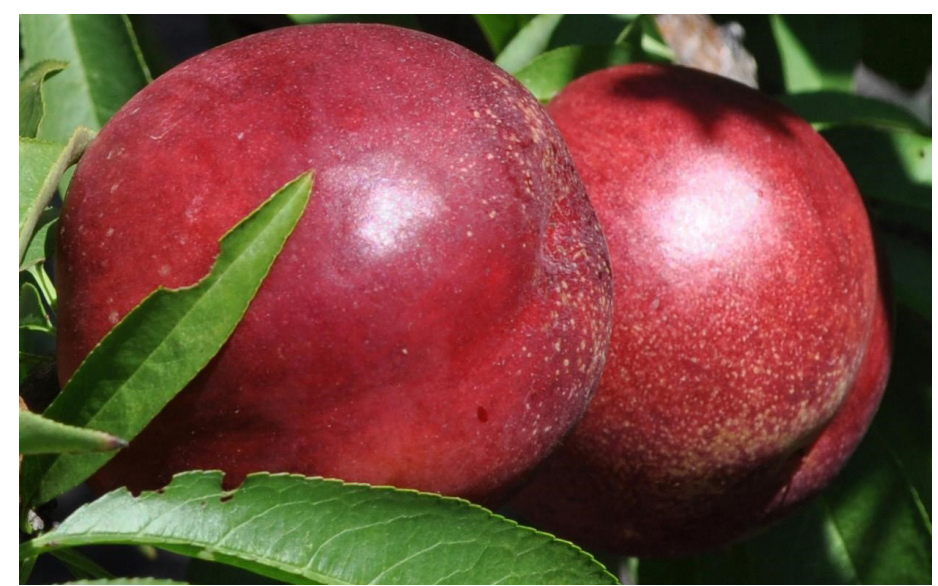

Figura 30. 'Sunmist'

\section{‘SUNCOAST'-375 UNIDADES DE FRÍO}

'Suncoast' es un cultivar de nectarina de carne fundida no patentado lanzado en 1995. Los árboles de 'Suncoast' son vigorosos y semi-esparcidos. Los frutos de 'Suncoast' tienen pulpa amarilla, desarrollan un $80 \%-90 \%$ de rubor rojo sobre un color de fondo amarillo y son semi-clingstone. Las frutas 'Suncoast' son ligeramente oblongas, sin puntas afiladas o protuberancias y tienden a ser ácidas. Las hojas y frutos de 'Suncoast' son resistentes a la mancha bacteriana. El FDP de la fruta 'Suncoast' es de 77 días, y la fruta madura de fines de abril hasta principios de mayo en Gainesville, Florida (Figura 31).

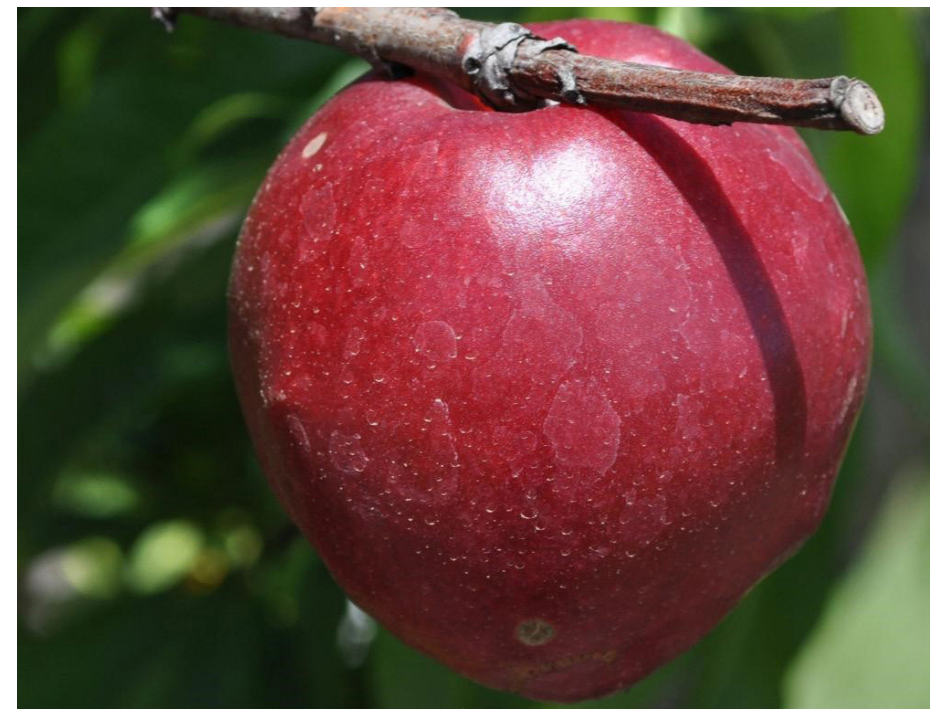

Figura 31. 'Suncoast'

\section{Florida Central y Sur-Central}

\section{'FLORDAPRINCE'—150 UNIDADES DE FRÍO}

'Flordaprince' fue lanzado por la UF en 1982 y su fruta tiene pulpa fundente. Ha sido un cultivar de durazno estándar de bajo requerimiento de horas frío en todo el mundo y es uno de los primeros en madurar. La fruta desarrolla un $80 \%$ de rubor rojo con rayas rojas oscuras sobre una base de color amarillo. Los frutos de 'Flordaprince' son grandes, uniformemente firmes y amarillos, con hueso semi-clingstone. La fruta madura entre 7 y 10 días antes que 'TropicBeauty' en Gainesville, Florida, con un FDP de 78 días (Figura 32).

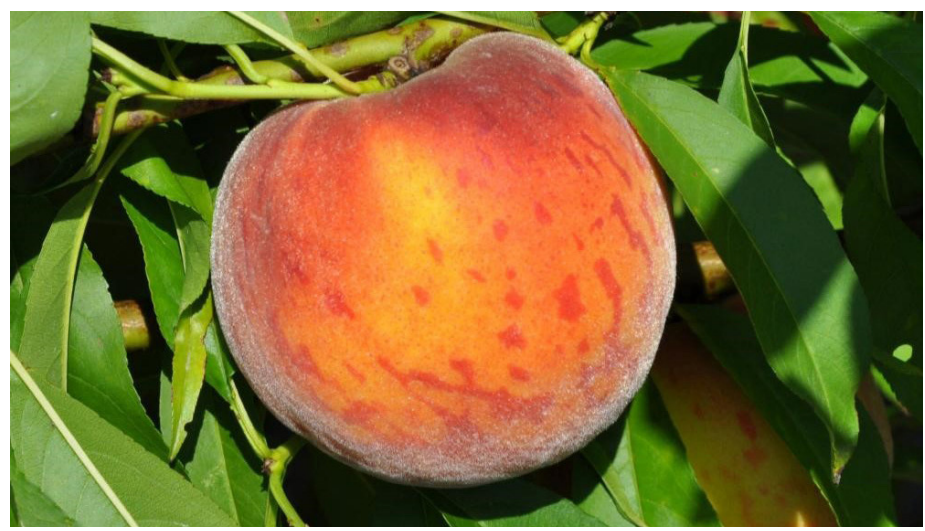

Figura 32. 'Flordaprince'

\section{‘FLORDAGLO'-150 UNIDADES DE FRÍO}

'Flordaglo' es un cultivar de pulpa fundida lanzado por la UF en 1988. La fruta desarrolla 50\%-60\% de rubor rojo con rayas, sobre un color de base blanco. La fruta 'Flordaglo' es de maduración temprana, semi-clingstone y resistente a la mancha bacteriana. La fruta madura a principios de mayo, aproximadamente 78 días después de la floración plena. La fruta 'Flordaglo' es ideal para las plantaciones en patios u operaciones de U-pick debido a la textura de pulpa fundente y su tendencia a mostrar moretones y abrasiones fácilmente (Figura 33).

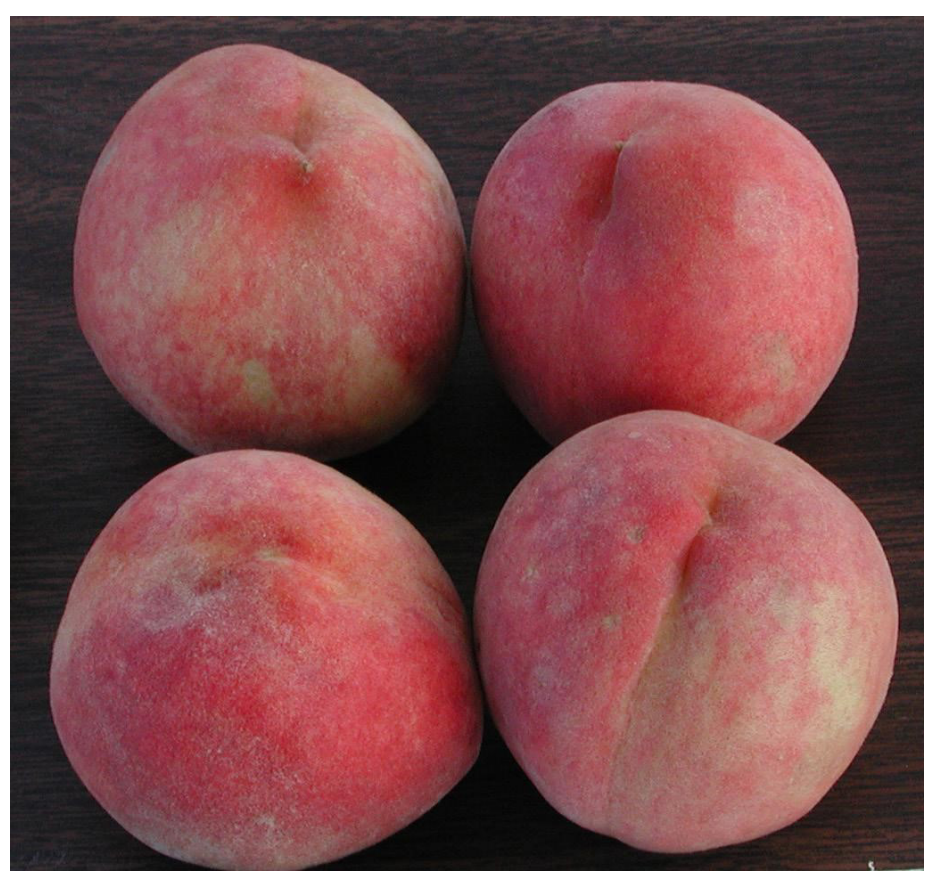

Figura 33. 'Flordaglo' 


\section{‘UFGOLD’—200 UNIDADES DE FRÍO}

'UFGold' es un durazno de pulpa amarilla no fundente lanzado por la UF en 1996. Los árboles 'UFGold' producen grandes cosechas anuales de fruta grande. Las frutas son de forma simétrica y desarrollan un rubor del 70\% al 90\% sobre un color de fondo amarillo anaranjado. La fruta 'UFGold' madura aproximadamente 80 días después de la floración, a principios de mayo (Gainesville, FL, Figura 34).

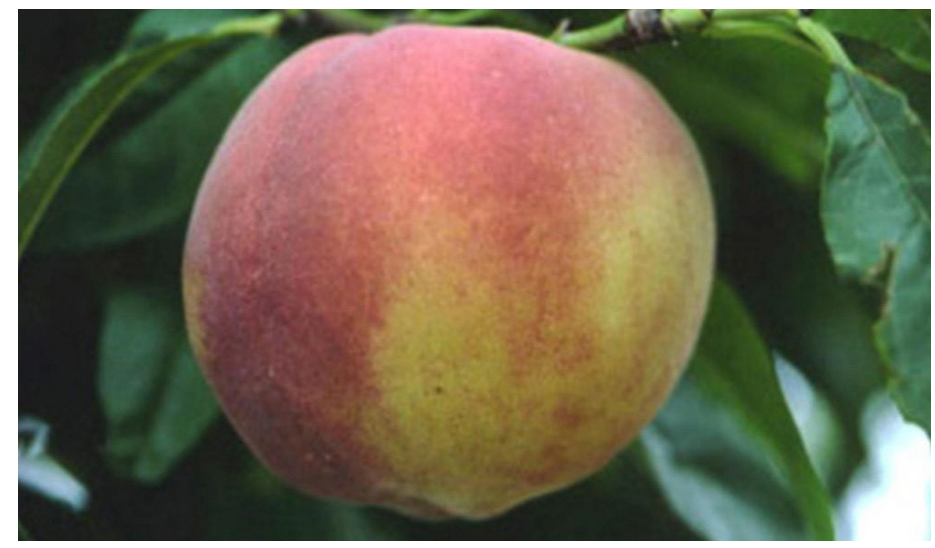

Figura 34. 'UFGold'

\section{‘TROPICSNOW'-225 UNIDADES DE FRÍO}

'TropicSnow' fue lanzado conjuntamente por la UF y Texas A\&M en 1989. Su fruto tiene pulpa blanca fundente y es de tipo semi-freestone. La fruta 'TropicSnow' desarrolla un rubor rojo del $40 \%-50 \%$ sobre un fondo blanco cremoso y tiene un sabor ácido muy bajo combinado con una excelente dulzura. 'TropicSnow' tiene un FDP de 90-97 días (Figura 35).

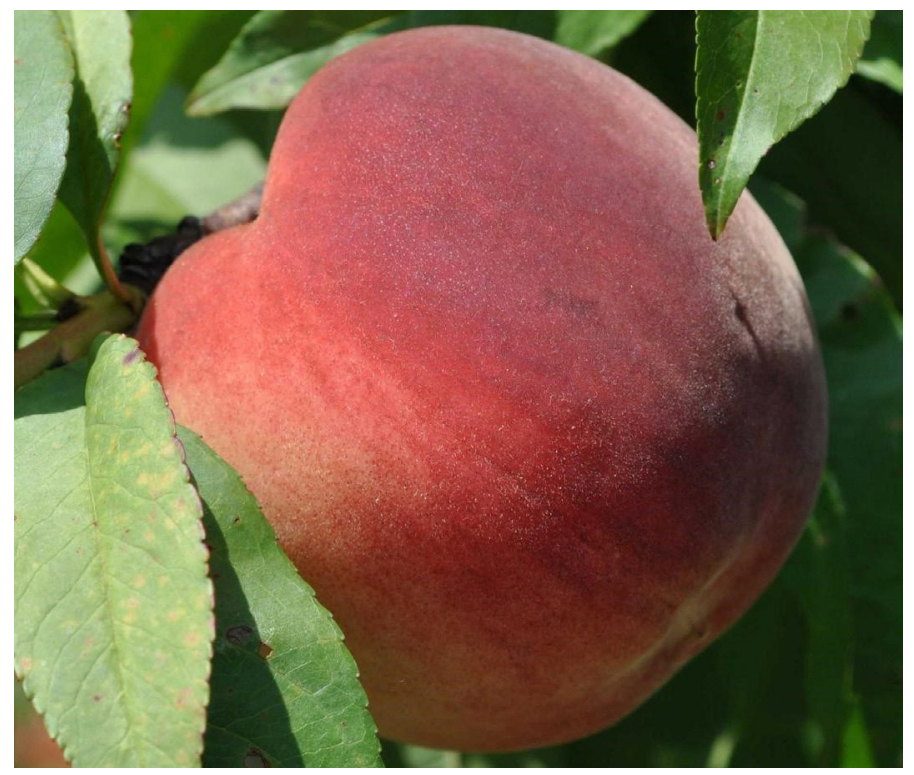

Figura 35. 'TropicSnow'

\section{Referencias}

Crisosto, C. H. 2002. "How do we increase peach consumption?” Acta Horticulturae 592: 601-605.

Fraisse, C. W., and A. Whidden. 2010. Chill Accumulation Monitoring and Forecasting. AE452. Gainesville: University of Florida Institute of Food and Agricultural Sciences. http://edis.ifas.ufl.edu/ae452

Krewer, G., T. Beckman, J. Chaparro, and W. Sherman, 2005. 'Gulfking' and 'Gulfcrest', new peaches for the lower coastal plain.” HortScience 40: 882.

Krewer, G. W., T. G. Beckman, J. X. Chaparro, and W. B. Sherman, 2008. "'Gulfcrimson' Peach." HortScience 43: 1596-1597.

Lopez, G., and T. M. Dejong. 2007. "Spring Temperatures Have a Major Effect on Early Stages of Peach Fruit Growth." Journal of Horticultural Science \& Biotechnology 82: 507-512.

Richardson, E. A., S. D. Seeley, and D. R. Walker. 1974. "A Model for Estimating the Completion of Rest for 'Redhaven'and 'Elberta' Peach Trees.' HortScience 9(4): 331-332.

Rouse, R. E., W. B. Sherman, and P. M. Lyrene, 2004. "'UFSun' Peach." Journal of the American Pomological Society 58: 108-110.

Sharpe, R. H., W. B. Sherman, and J. D. Martsolf. 1990."Peach Cultivars in Florida and Their Chilling Requirements." Acta Horticulturae 279: 191-197.

Sharpe, R. H., T. E. Webb, and H. W. Lundy. 1954. "Peach Cultivar Tests." Proceedings of the Florida State Horticultural Society 67: 245-246.

Sherman, W. B., P. M. Lyrene, and R. H. Sharpe. 1996. "Low-Chill Peach and Nectarine Breeding at the University of Florida." Florida State Horticultural Society 109: 222-223.

Weinberger, J. H. 1956. "Prolonged Dormancy Trouble in Peaches in the Southeast in Relation to Winter Temperatures." Proceedings of the American Society for Horticultural Science 67: 107-112. 
Tabla 1. Cultivares de durazno y nectarina recomendados para Florida.

\begin{tabular}{|c|c|c|c|}
\hline Cultivar* & Año de lanzamiento & Estado de la patente & Potencial de mercadeo \\
\hline \multicolumn{4}{|l|}{ Durazno } \\
\hline 'UFBest' & 2012 & Patentado & Comercial \\
\hline 'Gulfsnow' & 2012 & Patente pendiente & Comercial \\
\hline 'Flordabest' & 2009 & Patentado & Comercial \\
\hline 'Gulfcrimson' & 2009 & Patentado & Comercial \\
\hline 'UFGlo' & 2009 & Patentado & Comercial \\
\hline 'UFOne' & 2008 & Patentado & Comercial \\
\hline 'UFSharp' & 2006 & Patentado & Patio/U-pick \\
\hline 'UFSun' & 2004 & Patentado & Comercial \\
\hline 'Gulfking' & 2004 & Patentado & Comercial \\
\hline 'Gulfcrest' & 2004 & Patentado & Comercial \\
\hline 'UFBeauty' & 2002 & Patentado & Comercial \\
\hline 'UFO' & 2002 & Patentado & Comercial/Patio/U-Pick \\
\hline 'Gulfprince' & 2002 & Patentado & Patio/U-pick \\
\hline 'UFBlaze' & 2002 & Patentado & Patio/U-pick \\
\hline 'UF2000' & 2000 & Patentado & Patio/U-pick \\
\hline 'UFGold' & 1996 & Patentado & Patio/U-pick \\
\hline 'Flordadawn' & 1989 & No Patentado & Patio/U-pick \\
\hline 'TropicSnow' & 1989 & No Patentado & Patio/U-pick \\
\hline 'Flordacrest' & 1988 & No Patentado & Patio/U-pick \\
\hline 'Flordaglo' & 1988 & No Patentado & Patio/U-pick \\
\hline 'TropicBeauty' & 1988 & No Patentado & Comercial/Patio/U-Pick \\
\hline 'Flordaprince' & 1982 & No Patentado & Patio/U-pick \\
\hline 'Flordaking' & 1978 & No Patentado & Patio/U-pick \\
\hline \multicolumn{4}{|l|}{ Nectarina } \\
\hline 'UFRoyal' & 2009 & Patentado & Comercial \\
\hline 'Sunbest' & 2001 & Patentado & Comercial \\
\hline 'UFQueen' & 1998 & Patentado & Comercial \\
\hline 'Sunmist' & 1994 & No Patentado & Patio/U-pick \\
\hline 'Sunraycer' & 1993 & No Patentado & Comercial/Patio/U-Pick \\
\hline 'Suncoast' & 1993 & No Patentado & Patio/U-pick \\
\hline \multicolumn{4}{|c|}{$\begin{array}{l}\text { *: Todos los cultivares de durazno y nectarina de pulpa fundente lanzados por el programa de mejoramiento de la Universidad de Florida } \\
\text { comienzan con los prefijos 'Florida' 'S 'Sun', respectivamente. De manera similar, todos los cultivares de durazno y nectarina de pulpa no } \\
\text { fundente comparten el prefijo 'UF'. Los lanzamientos de la cooperativa entre la Universidad de Florida, Universidad de Georgia y USDA-ARS, } \\
\text { tienen el prefijo ‘Gulf'. }\end{array}$} \\
\hline
\end{tabular}


Tabla 2. Acumulación de unidades de frío desde el 1 de noviembre hasta el 15 de febrero $\left(32^{\circ} \mathrm{F}-45^{\circ} \mathrm{F}\right)$. Datos obtenidos por el generador de informes de umbral de temperatura de FAWN: http://fawn.ifas.ufl.edu/tools/temperature_threshold/.

\begin{tabular}{|c|c|c|c|c|c|c|c|c|}
\hline \multirow[t]{2}{*}{ Año } & \multicolumn{8}{|c|}{ Ubicación } \\
\hline & $\begin{array}{c}\text { Tallahassee } \\
\text { *(Monticello) }\end{array}$ & $\begin{array}{l}\text { Jacksonville } \\
\text { *(Macclenny) }\end{array}$ & Alachua & $\begin{array}{c}\text { Orlando } \\
{ }^{*} \text { (Avalon) }\end{array}$ & Lake Alfred & Frostproof & Fort Pierce & Immokalee \\
\hline 2000-2001 & $N A^{* *}$ & NA & 582 & 374 & 314 & NA & 210 & 202 \\
\hline 2001-2002 & NA & NA & 391 & 151 & 134 & NA & 88 & 86 \\
\hline $2002-2003$ & NA & 714 & 712 & 368 & 317 & NA & 253 & 247 \\
\hline 2003-2004 & 647 & 490 & 516 & 211 & 192 & NA & 103 & 177 \\
\hline 2004-2005 & 571 & 510 & 495 & 182 & 170 & NA & 129 & 174 \\
\hline 2005-2006 & 570 & 529 & 530 & 208 & 193 & 162 & 147 & 184 \\
\hline 2006-2007 & 540 & 442 & 419 & 82 & 101 & 61 & 64 & 66 \\
\hline 2007-2008 & 512 & 440 & 385 & 120 & 123 & 72 & 49 & 66 \\
\hline 2008-2009 & 517 & 505 & 490 & 251 & 246 & 160 & 138 & 196 \\
\hline 2009-2010 & 664 & 519 & 503 & 356 & 306 & 281 & 235 & 237 \\
\hline 2010-2011 & 778 & 679 & 646 & 352 & 371 & 295 & 223 & 227 \\
\hline 2011-2012 & 452 & 333 & 343 & 127 & 115 & 108 & 86 & 94 \\
\hline
\end{tabular}


Tabla 3. Requisitos de unidades de frío, características de flores y hojas, resistencia a enfermedades y conveniencia para cultivo comercial/patio de cultivares de durazno y nectarina con bajo requerimiento de frío del programa de fitomejoramiento de fruta de hueso de la Universidad de Florida.

\begin{tabular}{|c|c|c|c|c|c|c|c|}
\hline \multirow[b]{2}{*}{ Durazno } & \multicolumn{2}{|c|}{$\begin{array}{c}\text { Temperatura promedio de } \\
\text { enero }^{2}\end{array}$} & \multirow[t]{2}{*}{$\begin{array}{l}\text { Unidades de frío } \\
\text { estimadas }\end{array}$} & \multirow[t]{2}{*}{$\begin{array}{l}\text { Tipo de } \\
\text { flory }\end{array}$} & \multirow[t]{2}{*}{$\begin{array}{l}\text { Botones } \\
\text { florales }^{x}\end{array}$} & \multirow[t]{2}{*}{$\begin{array}{c}\text { Glándulas de } \\
\text { hojas }^{w}\end{array}$} & \multirow[t]{2}{*}{$\begin{array}{c}\text { Resistencia } \\
\text { mancha bacterialv }\end{array}$} \\
\hline & ${ }^{\circ} \mathbf{F}$ & ${ }^{\circ} \mathrm{C}$ & & & & & \\
\hline 'UFSun' & 63.3 & 17.4 & 100 & $\mathrm{~S}$ & 10 & $\mathrm{R}$ & 7 \\
\hline 'UFBest' & 66.2 & 19.0 & 100 & $\mathrm{~S}$ & 10 & $\mathrm{R}$ & 10 \\
\hline 'UFOne' & 63.5 & 17.5 & 150 & $\mathrm{~S}$ & 8 & G & 10 \\
\hline 'TropicBeauty' & 64.0 & 17.8 & 150 & $\mathrm{~S}$ & 8 & $\mathrm{R}$ & 5 \\
\hline 'Flordaprince' & 64.0 & 17.8 & 150 & $S$ & 8 & $\mathrm{R}$ & 4 \\
\hline 'Flordaglo' & 64.0 & 17.8 & 150 & $\mathrm{~S}$ & 9 & $\mathrm{R}$ & 8 \\
\hline 'UFBeauty' & 59.0 & 15.0 & 150 & $S$ & 8 & G & 10 \\
\hline 'UFGold' & 62.0 & 16.7 & 200 & $S$ & 9 & $\mathrm{R}$ & 9 \\
\hline 'TropicSnow' & 61.0 & 16.1 & 225 & $\mathrm{~S}$ & 9 & $\mathrm{R}$ & 8 \\
\hline 'UFO' & 61.0 & 16.1 & 250 & NS & 8 & $\mathrm{R}$ & 10 \\
\hline 'Flordabest' & 61.0 & 16.1 & 250 & $S$ & 10 & $\mathrm{R}$ & 9 \\
\hline 'UF2000' & 59.0 & 15.0 & 300 & $S$ & 9 & $\mathrm{R}$ & 9 \\
\hline 'UFBlaze' & 62.0 & 16.7 & 300 & $S$ & 8 & G & 10 \\
\hline 'Flordadawn' & 62.0 & 16.7 & 200 & $\mathrm{~S}$ & 9 & G & 10 \\
\hline 'UFSharp' & 59.0 & 14.9 & 325 & $S$ & 9 & G & 9 \\
\hline 'Flordacrest' & 58.0 & 14.4 & 350 & $\mathrm{~S}$ & 8 & G & 10 \\
\hline 'Gulfking' & 56.0 & 13.5 & 350 & $\mathrm{~S}$ & 9 & $\mathrm{R}$ & 10 \\
\hline 'Gulfsnow' & 53.0 & 13.0 & 400 & $S$ & 10 & G & 10 \\
\hline 'UFGlo' & 53.0 & 13.0 & 400 & $S$ & 10 & $\mathrm{R}$ & 10 \\
\hline 'Gulfprince' & 53.0 & 13 & 400 & $\mathrm{~S}$ & 9 & $\mathrm{R}$ & 10 \\
\hline 'Gulfcrimson' & 56.0 & 13.5 & 400 & $S$ & 9 & $\mathrm{R}$ & 10 \\
\hline 'Flordaking' & 58.0 & 14.4 & 450 & NS & 6 & G & 10 \\
\hline 'Gulfcrest' & 54.0 & 13.6 & 525 & NS & 9 & G & 10 \\
\hline \multicolumn{8}{|l|}{ Nectarina } \\
\hline 'Sunbest' & 61.0 & 16.6 & 225 & $\mathrm{~S}$ & 9 & $\mathrm{R}$ & 9 \\
\hline 'UFQueen' & 61.0 & 16.1 & 250 & NS & 9 & $\mathrm{R}$ & 8 \\
\hline 'Sunraycer' & 61.0 & 16.1 & 250 & NS & 8 & $\mathrm{R}$ & 10 \\
\hline 'UFRoyal' & 61.0 & 16.1 & 250 & $S$ & 9 & $\mathrm{R}$ & 10 \\
\hline 'Sunmist' & 60.0 & 15.6 & 300 & $S$ & 8 & G & 8 \\
\hline 'Suncoast' & 58.0 & 14.0 & 375 & NS & 9 & $\mathrm{R}$ & 10 \\
\hline \multicolumn{8}{|c|}{$\begin{array}{l}\text { ¿Adaptado de Weinberger (1956) y Sharpe (1990). Las áreas con estas temperaturas medias en enero o aún más bajas, proporcionarán } \\
\text { suficiente frío para que este durazno crezca con éxito. } \\
\text { y } S=\text { vistoso, NS }=\text { no vistoso } \\
\times 1=10 \% \text { conjunto de botones florales a } 10=100 \% \text { conjunto de botones florales } \\
\text { w } G=\text { globoso, } R=\text { reniforme } \\
\text { v } 1=\text { menos resistente a } 10=\text { más resistente }\end{array}$} \\
\hline
\end{tabular}




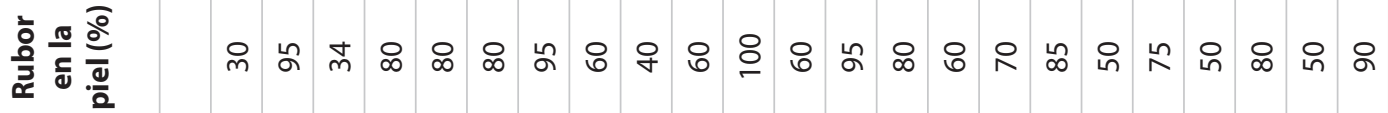
道

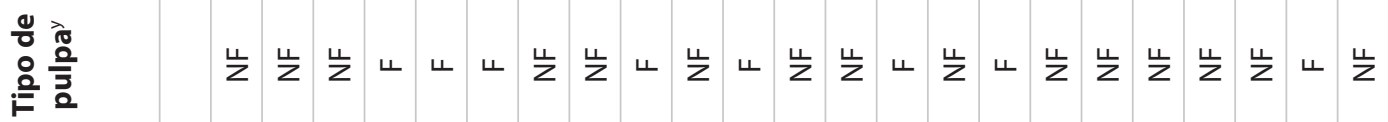

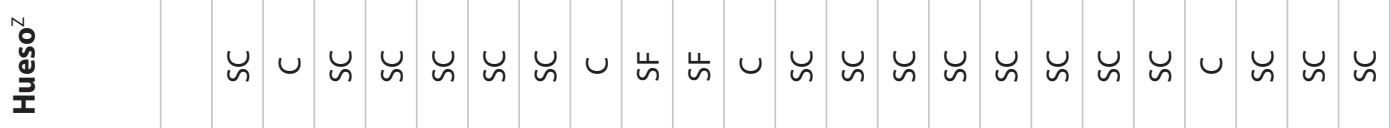
气

\begin{tabular}{|c|c|c|c|c|c|c|c|c|c|c|c|c|c|c|c|c|c|c|c|}
\hline 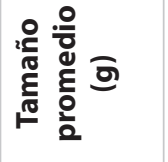 & & $\stackrel{\stackrel{m}{r}}{ }$ & $\stackrel{m}{m}$ & $\stackrel{m}{ \pm}$ & $\varnothing \infty$ & $\infty$ চ ন & $\stackrel{ }{=}$ & $\stackrel{ }{\subsetneq}$ & $\stackrel{\infty}{0}$ & $\stackrel{R}{\stackrel{\infty}{m}}$ & 욤 & $\stackrel{ }{=}$ & ৪! & ह & 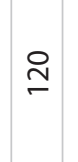 & 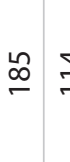 & $=\stackrel{\circ}{n}$ & $\stackrel{\stackrel{n}{m}}{n}$ & ஃ̊ \\
\hline 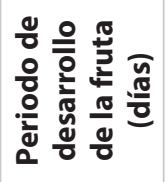 & & 8 & $\stackrel{\sim}{\infty}$ & nू ฉ & $\infty \infty_{\infty}^{\infty}$ & $\stackrel{\infty}{\sim} \stackrel{\infty}{\sim}$ & $\infty$ & 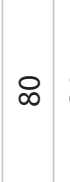 & ఏ & nू $\infty$ & n & $\stackrel{m}{\infty}$ & 8 & $\stackrel{2}{\Sigma} \stackrel{n}{\wedge}$ & 옷 & $\stackrel{0}{\circ}$ & $\stackrel{?}{=}$ & $\alpha$ & $\stackrel{\circ}{\circ}$ \\
\hline & $\begin{array}{l}\stackrel{0}{\mathfrak{N}} \\
\vdots \\
\vdots \\
0\end{array}$ & 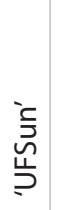 & 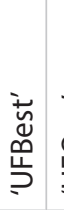 & 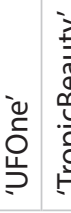 & 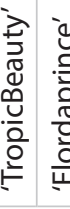 & 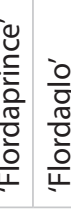 & 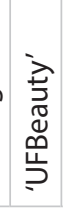 & 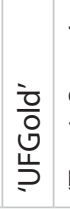 & 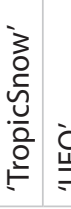 & 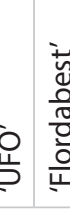 & 客 & $\begin{array}{l}i \\
\text { N } \\
\frac{N}{0} \\
\text { P } \\
?\end{array}$ & 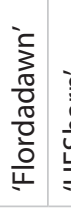 & 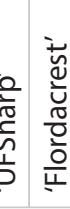 & 它 & 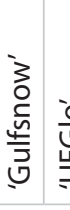 & 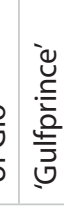 & 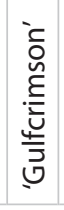 & $\begin{array}{l}\frac{i}{9} \\
\frac{5}{5} \\
\frac{5}{0} \\
\frac{0}{4} \\
\frac{0}{14}\end{array}$ \\
\hline
\end{tabular}




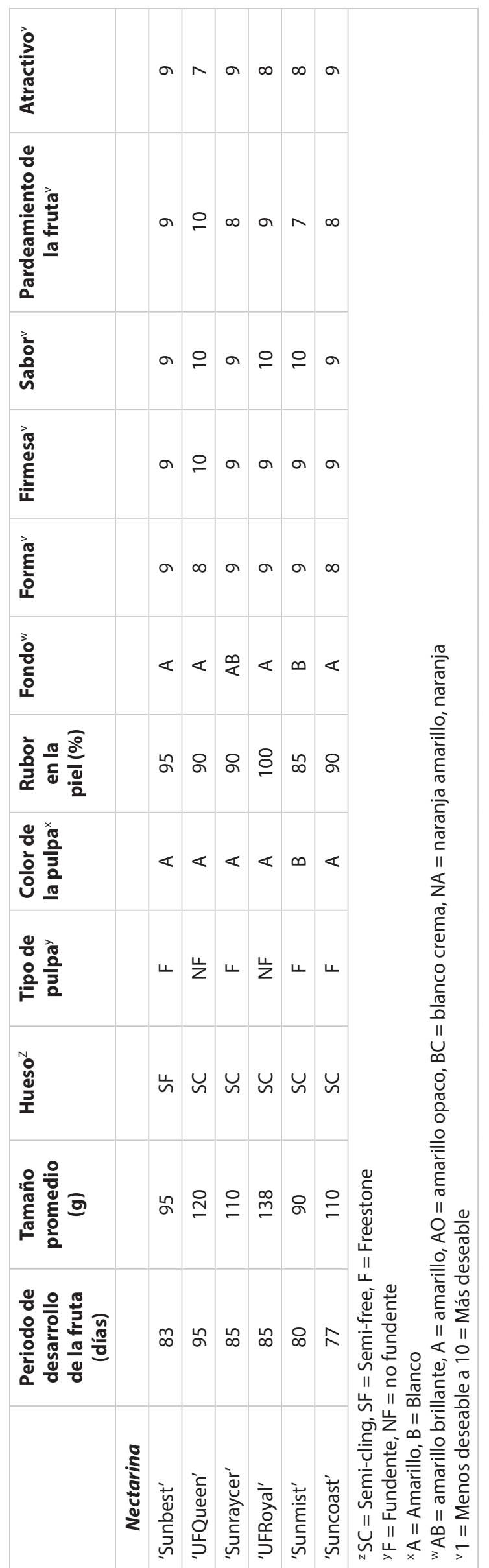

